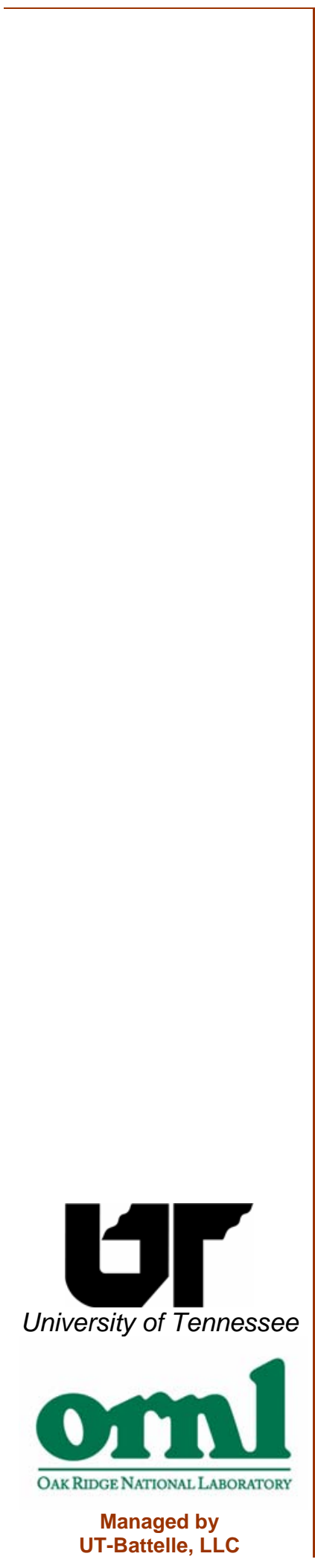

Final Technical Report

\title{
Ultrasonic Processing of Materials
}

June 2006

\section{Principal Investigators:}

Thomas T. Meek

University of Tennessee

Qingyou Han

Oak Ridge National Laboratory 


\section{DOCUMENT AVAILABILITY}

Reports produced after January 1, 1996, are generally available free via the U.S. Department of Energy (DOE) Information Bridge.

Web site http://www.osti.gov/bridge

Reports produced before January 1, 1996, may be purchased by members of the public from the following source.

National Technical Information Service

5285 Port Royal Road

Springfield, VA 22161

Telephone 703-605-6000 (1-800-553-6847)

TDD 703-487-4639

Fax 703-605-6900

E-mail info@ntis.fedworld.gov

Web site http://www.ntis.gov/support/ordernowabout.htm

Reports are available to DOE employees, DOE contractors, Energy Technology Data Exchange (ETDE) representatives, and International Nuclear Information System (INIS) representatives from the following source.

Office of Scientific and Technical Information

P.O. Box 62

Oak Ridge, TN 37831

Telephone 865-576-8401

Fax 865-576-5728

E-mail reports@adonis.osti.gov

Web site http://www.osti.gov/contact.html 


\section{FINAL TECHNICAL REPORT}

Project Title: $\quad$ Ultrasonic Processing of Materials

Award Number: $\quad$ DE-FC07-01ID14256

Project Period: $\quad$ September 1, 2001-December 31, 2004

$\begin{array}{lll}\text { Principal Investigators: } & \text { Thomas T. Meek } & \text { Qingyou Han } \\ & \text { (865) 974-0940 } & \text { (865) 574-4352 } \\ & \text { tmeek7@utk.edu } & \text { hanq@ornl.gov }\end{array}$

Authors:

Thomas T. Meek

Qingyou Han

(865) 974-0940

(865) 574-4352

tmeek7@utk.edu

hanq@ornl.gov

Xiaogang Jian

Hanbing Xu

(865) 574-9956

(865)-576-3598

jianx@ornl.gov

xuh@ornl.gov

Recipient:

The University of Tennessee

Materials Science and Engineering Department

434 Dougherty Engineering Bldg.

Knoxville, TN 37996-2200

Project Team:

University of Tennessee

Thomas T. Meek

Xiaogang Jian

(865) 974-0940

(865) 574-9956

tmeek7@utk.edu

jianx@ornl.gov

Hanbing Xu

(865)-576-3598

xuh@ornl.gov

\section{Oak Ridge National Laboratory}

Qingyou Han

(865) 574-4352

hanq@ornl.gov

\section{Industry Contacts}

Subodh Das, Secat, Inc.

J. W. Bope, Ohio Valley Aluminum Co.

Y. V. Murty, Carpenter Technologies Corp.

Ed Neeb, Sonics and Materials, Inc. 



\section{Ultrasonic Processing of Materials}

Thomas T. Meek, Xiaogang Jian, and Hanbing Xu University of Tennessee

Qingyou Han

Oak Ridge National Laboratory

June 2006

Prepared by OAK RIDGE NATIONAL LABORATORY

P.O. Box 2008

Oak Ridge, Tennessee 37831-6283

managed by

UT-Battelle, LLC

for the

U.S. DEPARTMENT OF ENERGY

under contract DE-AC05-00OR22725 


\section{Acknowledgments and Disclaimer}

\section{Acknowledgments}

This report is based upon work supported by the U.S. Department of Energy, Office of Energy Efficiency, Industrial Technologies Program, Industrial Materials for the Future (IMF) Program, under Award No. DE-FC07-01ID14256. The authors would like to thank Cailu Xu, E. C. Hatfield, and Tom Geer for their technical support, valuable comments and suggestions. The authors also wish to thank Secat, Inc.; Ohio Valley Aluminum Co.; Carpenter Technologies Corp.; and Sonics and Materials, Inc., for the valuable help they offered. Finally, we thank Peter Angelini, Oak Ridge National Laboratory, for project direction and review.

Research at Oak Ridge National Laboratory was sponsored by the U.S. Department of Energy, Office of Energy Efficiency and Renewable Energy, Industrial Technologies Program, under contract DEAC05-00OR22725 with UT-Battelle, LLC.

\section{Disclaimer}

This report was prepared as an account of work sponsored by an agency of the United States Government. Neither the United States Government nor any agency thereof, nor any of their employees, makes any warranty, express or implied, or assumes any legal liability or responsibility for the accuracy, completeness, or usefulness of any information, apparatus, product, or process disclosed, or represents that its use would not infringe privately owned rights. Reference herein to any specific commercial product, process, or service by trade name, trademark, manufacturer, or otherwise, does not necessarily constitute or imply its endorsement, recommendation, or favoring by the United States Government or any agency thereof. The views and opinions of authors expressed herein do not necessarily state or reflect those of the United States Government or any agency thereof.

\section{Proprietary Data Notice}

The authors have filed a patent application, "Method and Apparatus for Semi-Solid Material Processing” (UT-Battelle identification number 1448). The subject method is discussed in this report. 


\section{Contents}

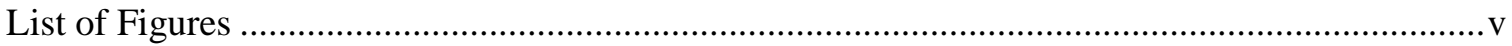

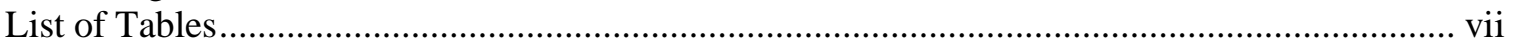

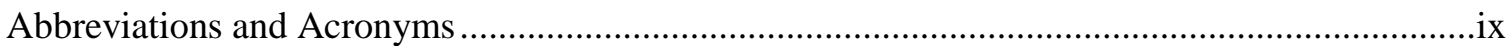

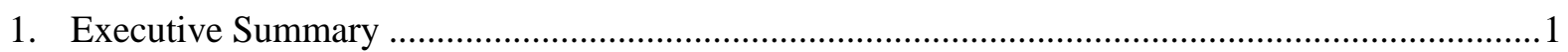

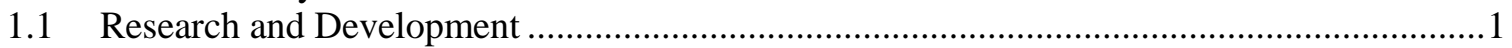

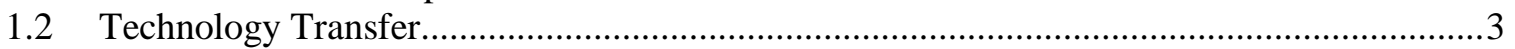

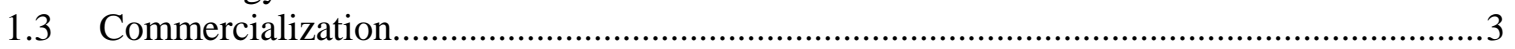

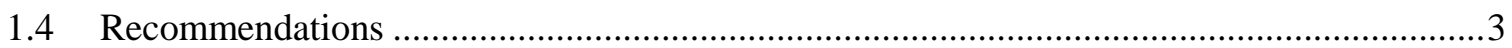

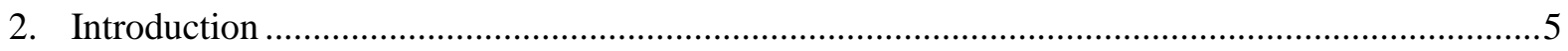

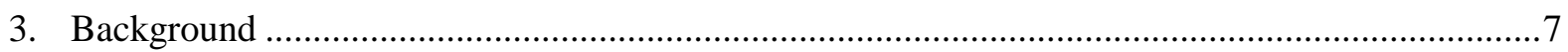

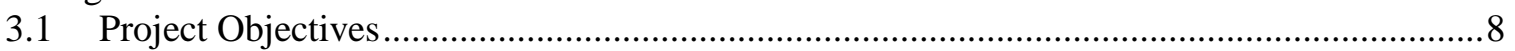

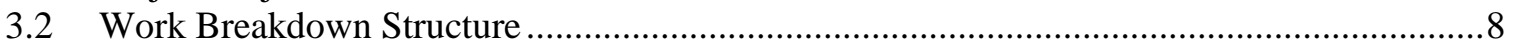

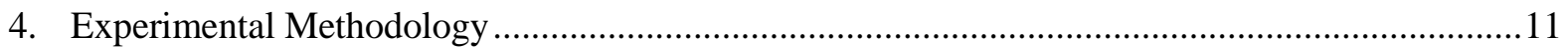

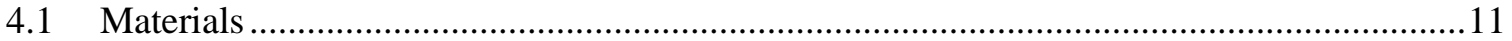

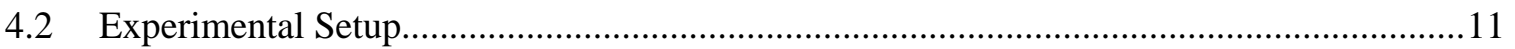

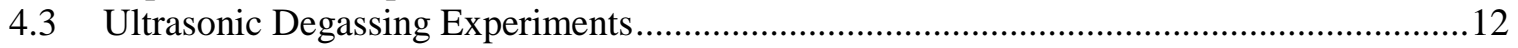

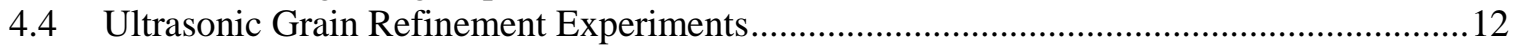

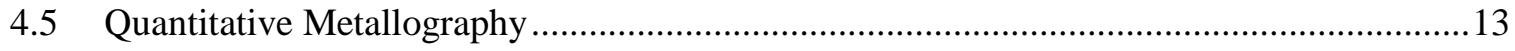

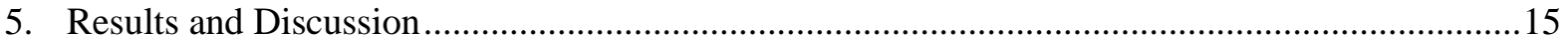

5.1 Coating Test to Protect Ultrasonic Radiator at High Temperature .....................................15

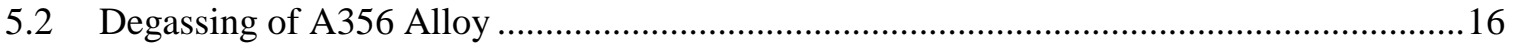

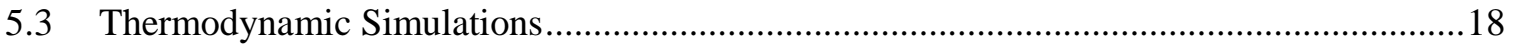

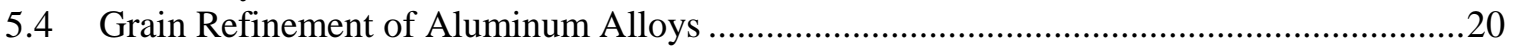

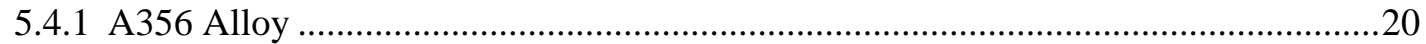

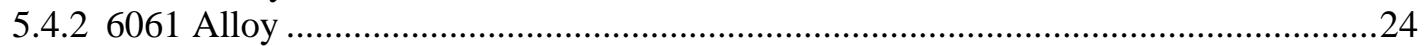

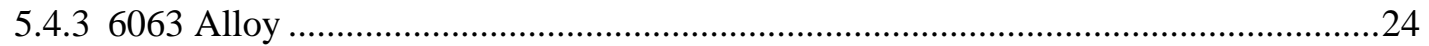

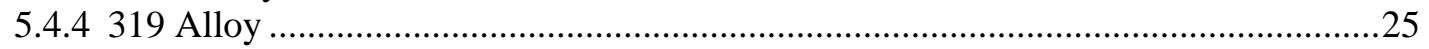

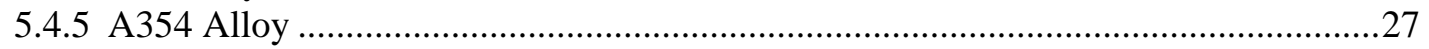

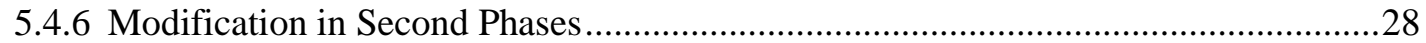

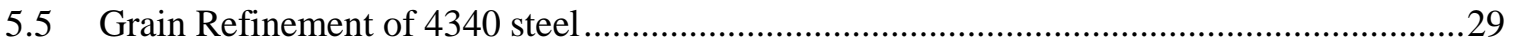

5.6 Parameters Affecting Grain Refinement during Ultrasonic Processing ..............................30

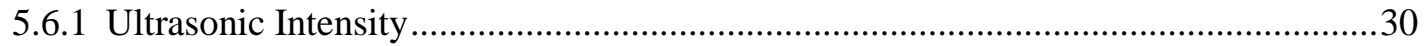

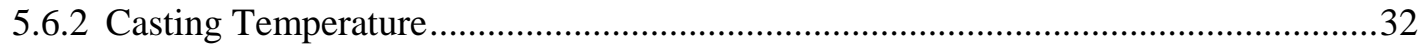

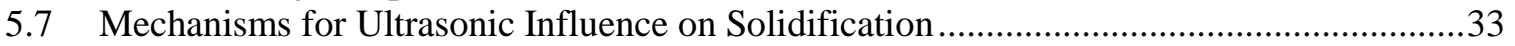

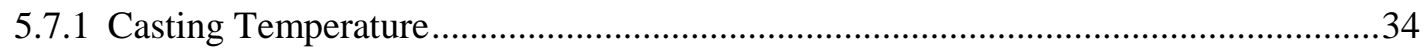

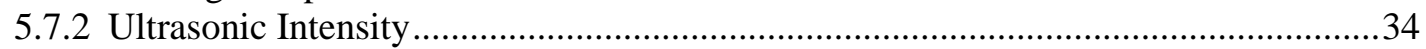

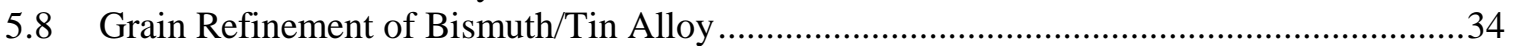




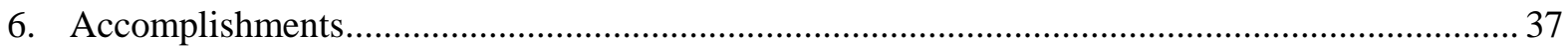

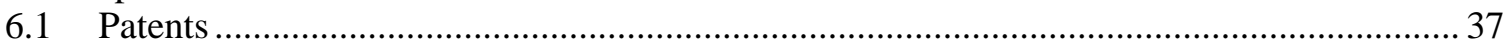

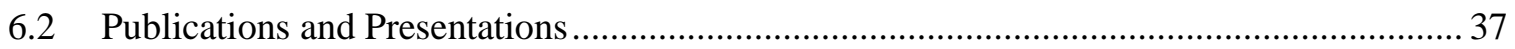

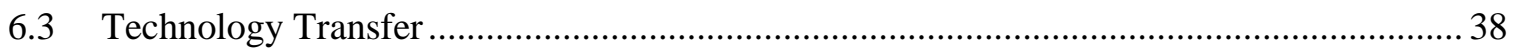

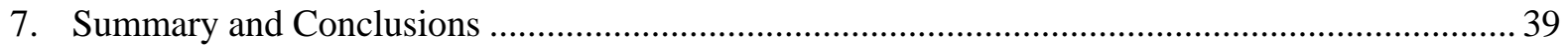

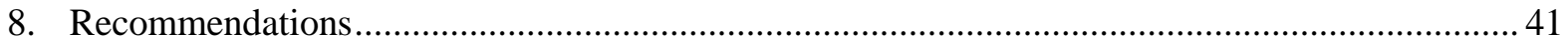

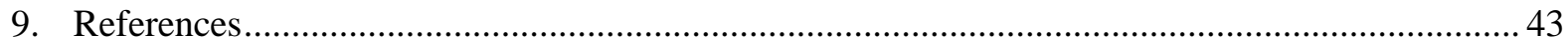

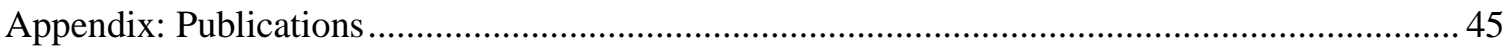




\section{List of Figures}

4.1 Experimental apparatus for the ultrasonic vibrator/metal injection assembly

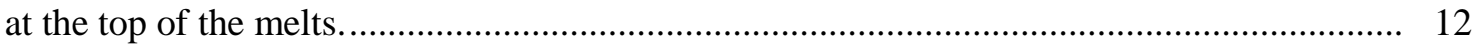

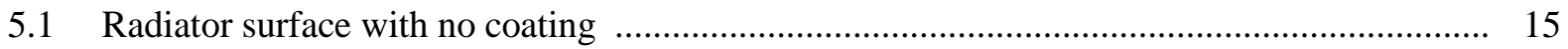

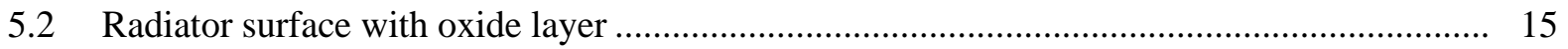

5.3 Radiator surface with graphite coating .......................................................................... 15

$5.4 \quad$ Radiator surface with boron nitride coating .................................................................... 16

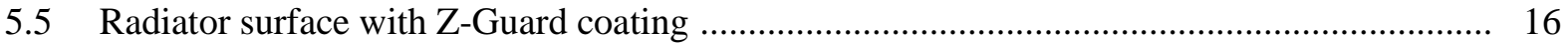

5.6 Porosity in RPT specimens made from the melt and subjected to various ultrasonic

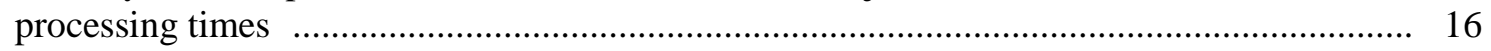

5.7 Effect of processing time on porosity for varying melt sizes ........................................... 17

5.8 RPT specimens at various ultrasonic processing times ..................................................... 17

5.9 Measured density of the RPT specimen as a function of ultrasonic processing time in melt at different processing temperatures. .................................................................. 18

5.10 Temperature vs solid fraction curve for selected aluminum alloys. .................................... 19

5.11 Microstructure of A356 specimens without (a) and with (b) intermittent ultrasonic

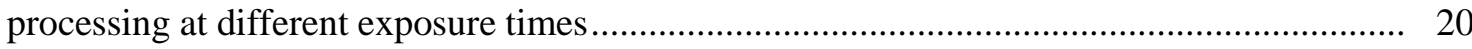

5.12 Microstructure of A356 specimens without and with isothermal ultrasonic processing

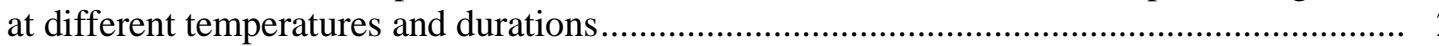

5.13 Microstructure of A356 specimens without and with isothermal ultrasonic processing at different temperatures and durations

5.14 Microstructure of A356 specimens without and with ultrasonic processing applied to the solid part of the solidifying specimen and then cooled in a metal mold ....................... 23

5.15 Microstructure of 6061 alloy without and with ultrasonic vibration ................................... 24

5.16 Microstructure of 6063 alloy without and with ultrasonic vibration ................................... 25

5.17 Measured cooling curve of aluminum alloy 319, normal condition. .................................... 26

5.18 Microstructure of aluminum alloy 319 without and with $100 \%$ amplitude vibration

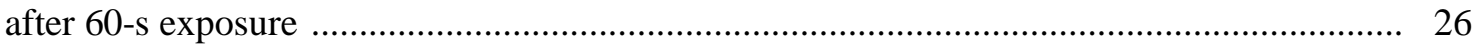

5.19 Microstructure of A354 alloy without and with ultrasonic processing ................................ 27

5.20 Effect of ultrasonic vibration on eutectic silicon structure (small dark structures) in aluminum alloy A356 as seen under optical microscope ............................................... 28

5.21 Effect of ultrasonic vibration on eutectic silicon structure in aluminum alloy A356 as seen with SEM

5.22 Microstructure of 4340 steel without and with $100 \%$ ultrasonic amplitude and 120 -s exposure time

5.23 Microstructure of aluminum alloy A356 processed with varying ultrasonic amplitudes 
5.24 Quantitative analysis of the effect of ultrasonic amplitude

5.25 Effect of casting temperature on as-cast microstructure of A356 alloy with ultrasonic vibration at $70 \%$ amplitude for $60 \mathrm{~s}$

5.26 Quantitative analysis of the effect of casting temperature with ultrasonic vibration of $70 \%$ amplitude

5.27 Microstructure of bismuth/tin alloy without and with $400-\mathrm{kHz}$ vibration and varying ultrasonic amplitude 


\section{List of Tables}

4.1 Composition of aluminum alloys used in ultrasonics project ........................................... 11

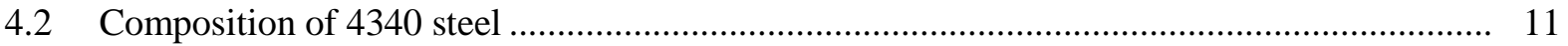

5.1 Characteristics of eutectic silicon particles corresponding to specimens in Fig. 5.20 ............ 28 



\section{Abbreviations and Acronyms}

$\begin{array}{ll}\text { AFS } & \text { American Foundry Society } \\ \text { ASM } & \text { American Society of Metals } \\ \text { bcc } & \text { body-centered cubic } \\ \text { DC } & \text { direct chill } \\ \text { DOE } & \text { U.S. Department of Energy } \\ \text { fcc } & \text { face-centered cubic } \\ \text { GM } & \text { General Motor Corporation } \\ \text { IMF } & \text { Industrial Materials for the Future } \\ \text { ITP } & \text { North American Die Casting Association } \\ \text { NADCA } & \text { Oak Ridge National Laboratory } \\ \text { ORNL } & \text { piezoelectric lead zirconate titanate } \\ \text { PZT } & \text { reduced-pressure test } \\ \text { RPT } & \text { scanning electron microscope/microscopy } \\ \text { SEM } & \text { The Minerals, Metals, and Materials Society } \\ \text { TMS } & \text { University of Tennessee } \\ \text { UT } & \end{array}$





\section{Executive Summary}

\subsection{Research and Development}

This project was conducted in response to an Industrial Materials for the Future (IMF) university call for proposals. It was primarily a feasibility study to determine the impact of a new breakthrough technology, ultrasonic processing, on various industries, including steel, aluminum, metal casting, and forging.

Ultrasonic processing has been used in the generation of aerosols, the refinement of grain structure in crystallized solids, and the enhancement of diffusion in liquids and solids. It has also been employed to dry powders and other materials. Other areas of ultrasonic processing include machining operations (drilling and cutting) and welding and bonding. Ultrasonic bonding has been widely used in the integrated circuit industry for many years. Ultrasonic cleaning of materials and ultrasonic degassing of liquids has also found wide acceptance. Many studies on organic and metallic systems have demonstrated the importance of this technique in influencing the final microstructure of materials. However, there has been little commercial implementation of ultrasonic techniques in materials processing. In addition, most studies have been empirical and phenomenological rather than quantitative.

The goals of the project were to evaluate core principles and establish quantitative bases for the ultrasonic processing of materials, and to demonstrate key applications in the areas of grain refinement of alloys during solidification and degassing of alloy melts. This study focused on two classes of materials - aluminum alloys and steels - and demonstrated the application of ultrasonic processing during ingot casting.

For the purpose of the experiments an experimental apparatus was built that produces ultrasonic vibration at a frequency of $20 \mathrm{kHz}$. In the experiments on use of ultrasonic techniques for grain refinement, the targeted materials were 4340 steel and the aluminum alloys A356, A354, 319, 3004, 6061, and 6063. Thermodynamic simulations were carried out using the Scheil model simulation to determine the temperature vs solid fraction curve of the alloys.

Experiments were carried out on aluminum alloys with two different ultrasonic vibration methods: isothermal/intermittent vibration or continuous vibration. Experiments focused on identifying parameters affecting spherical grain formation-i.e., casting temperature, intensity of ultrasonic vibration, grain refiners, and vibration times.

For the isothermal vibration experiments, aluminum alloy A356 was used. Ultrasonic vibrations were introduced into the melt isothermally or intermittently. Fine globular grains were obtained in the specimen treated with intermittent ultrasonic vibrations for $5 \mathrm{~s}$. However, dendrites were not completely broken down into fine grains in the isothermally processed specimens. This may imply that dendrite fragmentation has a limited effect on the formation of globular/nondendrite microstructure in the acoustically processed melt. Acoustically induced heterogeneous nucleation seems to be the dominant mechanism for the formation of a globular microstructure.

Steel and aluminum alloys were tested in experiments in which ultrasonic vibrations were introduced continuously into solidifying specimens. Results show that ultrasonic vibrations have a significant effect on the as-cast microstructure of many aluminum alloys and specialty steels. Under various 
experimental conditions, fine globular grains were obtained instead of large dendritic grains. Under some conditions, the size of the primary aluminum grains reached $20 \mu \mathrm{m}$, much smaller than the grain size obtainable using the best current grain refiners. The morphology of the eutectic silicon phase was also altered from a coarse, long acicular form to an extremely fine form.

The continuous ultrasonic vibration method, along with varying of the ultrasonic amplitude, was also used to investigate the effect of ultrasound intensity on grain structures. With increasing ultrasonic amplitude, the primary aluminum grains became less dendritic and more spherical. In addition, the eutectic silicon phase was refined and its morphology changed from coarse and acicular or lamellar form to small rosette-like form. High acoustic intensity favored the formation of small, spherical primary aluminum grains.

The effect of casting temperature on grain structures was then investigated. Results showed that the size of the primary aluminum grain decreased with decreasing casting temperature, reached a minimum at $630^{\circ} \mathrm{C}$, and then increased slightly with slightly decreasing casting temperature.

Degassing of A356 alloy under ultrasonic vibration was also investigated. A steady-state hydrogen concentration was obtained within a few minutes of ultrasonic vibration, regardless of the initial hydrogen concentration in the melt. The dynamics of hydrogen evolution as a function of processing time, melt temperature, and initial hydrogen concentrations was investigated. It may be that ultrasonic vibration can be used to reduce the formation of porosity in aluminum alloys.

A second experimental apparatus was built for the investigation of grain refinement under highintensity and high-frequency ultrasonic vibration. This apparatus enabled the power output to be adjusted between 0 and $300 \mathrm{~W}$, and provided frequencies of $250,400,600$, and $800 \mathrm{kHz} ; 1,1.2,1.4$ and $1.5 \mathrm{MHz}$; etc. In the first experiments, carried out using $400-\mathrm{kHz}$ ultrasonic vibration to treat a bismuth-tin alloy, grain refinement was observed. This was the first reported experiment to use highfrequency ultrasonic vibration for the purpose of grain refinement in any materials.

The results of this research clearly indicate that ultrasonic processing can be used to produce spherical grains that are much smaller than those produced with the most powerful grain refiners. Furthermore, materials with these spherical grains are suitable for semisolid metal processing, a new processing technology for producing high-quality components for critical applications. The experimental results suggest that ultrasonic processing has the potential for a more energy efficient scale-up for the production of critical metal components, leading to cost reductions, energy savings, and many other benefits.

Energy benefits from the results of this project, can occur through a number of avenues:

1. Result: Ultrasonics leads to much more rapid removal of hydrogen from molten aluminum.

a. Energy benefits accrue from less dross formation because of a shorter time at degassing temperature.

b. Productivity increases due to the shorter processing time.

c. Environmental benefits accrue from the elimination of fluorine gas from the process.

2. Result: Ultrasonics leads to much-finer-grained material.

a. Energy benefits can accrue from a reduction in time and temperature in the homogenization processes for steel and aluminum alloys. Steel currently requires $\sim 24 \mathrm{~h}$ homogenization; the 
new estimate for processing time is $16 \mathrm{~h}$. Aluminum currently requires $\sim 8 \mathrm{~h}$; the new process is estimated to require $6 \mathrm{~h}$.

b. Energy benefits can also accrue from reducing the scrap rate for steel or aluminum (currently $\sim 5 \%$; new process est. $\sim 3 \%$ ). This could occur in the following processes: direct chill casting, continuous casting, die casting, and permanent mold casting.

c. Energy benefits can also accrue by the elimination of grain refiners in aluminum processing.

\subsection{Technology Transfer}

Intellectual property has been generated from this research effort. A patent application has been filed; details are provided in Sect. 6.3. Several U.S. companies have signed nondisclosure agreements with Oak Ridge National Laboratory (ORNL) and are evaluating the technology.

\subsection{Commercialization}

This project was funded in response to a call for proposals under the IMF Industrial Technologies Program (ITP) of the U.S. Department of Energy (DOE). The goals of the project were to evaluate core principles and establish quantitative bases for the ultrasonic processing of materials, and to demonstrate key applications in the areas of grain refinement of alloys during solidification and degassing of alloy melts. This study focused on two classes of materials-aluminum alloys and steels - and demonstrated the application of ultrasonic processing during ingot casting. Project participants have used several mechanisms to inform industries of the research results and advance commercialization: (1) conducting review meetings at industrial sites and at ORNL; (2) making presentations at national meetings organized by the Minerals, Metals, and Materials Society (TMS), the American Society of Metals (ASM), and the American Foundry Society (AFS); and (3) making presentations at industrial locations and for organizations such as the North American Die Casting Association (NADCA) and AFS.

Companies who have expressed interest in the technology during this endeavor include Alcoa, Amcast Automotive, American Forging Association, Carpenter Technologies Corp., GM, IdraPrince, Holset Turbochargers, Lunt Manufacturing, Mercury Marine, NADCA, Ohio Valley Aluminum, Pyrotek, Queen City Forging, and Secat.

\subsection{Recommendations}

Future studies should determine the mechanism of ultrasonic vibration on the eutectic structures in aluminum alloys. It is highly recommended that research continue and that application and commercialization of this technology be pursued. There are a number of new applications for this technology. If incorporated into a die casting machine it may dramatically improve the integrity and properties of die castings and increase yield, thereby improving energy productivity. It may enable producing semisolid feedstock directly from molten metal, which should make this process more energy-efficient. It may also enable the forging industry to process new materials that are difficult to cast. The project research team is continuing to look for industrial partners with an interest in the next stage of scale-up of this technology. 



\section{Introduction}

This project was funded in response to a call for proposals under the Industrial Materials for the Future (IMF) Industrial Technologies Program (ITP), U.S. Department of Energy (DOE). The goals of the project were to evaluate core principles and establish quantitative bases for the ultrasonic processing of materials, and to demonstrate key applications in the areas of grain refinement of alloys during solidification and degassing of alloy melts. This study focused on two classes of materialsaluminum alloys and steels - and demonstrated the application of ultrasonic processing during ingot casting. The results could lead to significant energy savings in the aluminum, steel, metal casting, and forging industries.

The effects of ultrasound on the microstructure of alloys [1,2] include a reduction in grain size, control of columnar structure and formation of equiaxed grains, variation in the distribution and refinement of phases, improvement of material homogeneity, segregation control, and the uniform distribution of second phases and inclusions $[1,4]$. However, most studies have been empirical and phenomenological rather than quantitative. There has been only limited industrial-scale application of ultrasonics for manufacturing alloys, and only a few studies have addressed the fundamental nucleation mechanisms and the growth of grains $[1,4]$ during ultrasonically induced solidification. Thus, the mechanisms by which ultrasonic vibration affects spherical grain formation are not clear; and the effect of billet size is also not clear. In addition, the influence of ultrasonic vibration on the formation of eutectic phases is unknown. The lack of a fundamental understanding of the process and a quantitative basis for the ultrasonic processing of metals has meant limited application of highintensity ultrasonic vibration methods in industry, and therefore a loss of the energy and cost savings that would derive from use of this technology.

This project evaluated concepts and established a quantitative basis for the ultrasonic processing of materials. It demonstrated key applications in grain refinement of alloys during solidification and degassing of alloy melts. The study focused on two classes of materials-aluminum alloys and specialty steels - and demonstrated the application of ultrasonic processing during ingot casting. This investigation proposed to study the effect of varying the acoustic energy during melting and solidification. Various acoustic amplitudes were used in this study, and continuous acoustic input power from 0 to $1500 \mathrm{~W}$ was tested. Variables were acoustic amplitude, processing time, and casting temperature. Frequency was held constant at $20 \mathrm{KHz}$.

Project results provide a quantitative basis for hydrogen removal during degassing and grain size control during alloy solidification in an acoustic field. Novel methods have been proposed to produce spherical and fine-grained alloy microstructures for semisolid processing, forging, and die casting applications. These novel methods are described in the patent application cited in Sect. 6.1 of this report. It is expected that the results of the work will impact a wide range of alloy processing areas, including direct chill (DC) casting, continuous casting, vacuum arc remelting, and foundry processing in the areas of degassing, grain refinement, and the production of new and novel microstructures.

The research team for the project was composed of Dr. Tom T. Meek of the University of Tennessee, Knoxville (UTK), who was the primary investigator for this project; Ph.D. student Xiaogang Jian of UTK, who concentrated on the study on ultrasonic grain refinement; Dr. Hanbing Xu of UTK, who studied ultrasonic degassing; and Dr. Qingyou Han of ORNL, who led the research team and performed the thermodynamic simulations. Industrial support was provided by Dr. Subodh Das of Secat, Inc., and Dr. Y. V. Murty of Carpenter Technology Corporation. 



\section{Background}

Microstructure modification requires the introduction into the melt of a sufficient intensity of acoustic energy to set up a pressure variation that will initiate cavitation [1,4,5]. A minimum acoustic intensity of $10 \mathrm{~W} / \mathrm{cm}^{2}$ at $20 \mathrm{kHz}$ is required for cavitation to occur in the liquid form of most materials.

Calculations [5] have shown that the stresses created in a metal surface layer by the implosion of a cavitation bubble immediately adjacent to the surface or separated from it by a distance of a few radii amount to $\sim 13,000 \mathrm{~atm}$. The maximum and minimum pressures caused in a melt are given by the following equations [3]:

$$
\begin{aligned}
& p_{\text {max }}=p_{0}+\sqrt{2 \rho c I} P a, \\
& p_{\text {min }}=p_{0}-\sqrt{2 \rho c I} P a,
\end{aligned}
$$

where $p_{0}$ is the atmospheric pressure in pascals, $\rho$ the density in kilograms per cubic meter, $c$ the wave velocity of the melt in meters per second, and $I$ the wave energy density in the melt in watts per cubic meter. Thus, the application of ultrasonic energy to the melt results in instantaneous variation in the local pressure from the minimum to the maximum. The low pressure during cavitation creates tiny bubbles. At high pressures, the bubbles collapse and produce shock waves. The ultrasonically induced cavitations can be used for hydrogen removal (degassing) and microstructure modification.

The following three phenomena had been reported in the literature but had not been systematically investigated in the past. This research project was intended to investigate the following three phenomena.

1. Ultrasonically induced degassing. The tiny bubbles that form and then collapse during cavitation can serve as nuclei for the formation of hydrogen bubbles. These hydrogen bubbles formed can float out of the liquid. Since higher vibration intensity produces lower pressures, degassing efficiency is proportional to the intensity of vibration.

2. Ultrasonically induced grain nucleation. Ultrasonic vibration may affect nucleation in many ways [1,3]. Obviously, the liquidus temperature of the alloy is a function of pressure. The liquidus temperature decreases with increasing pressure. If ultrasonic energy is applied to a melt held close to its liquidus temperature, some regions in the melt may be superheated while other areas may be undercooled. At each location, the melt may undergo changes from undercooling to superheating at high frequencies. This may result in the formation of an increased number of solid nuclei. Another possibility is that the grain refiners added to the melt may also be affected by ultrasonic vibration, since each foreign particle can act as a nucleus and is most effective under a certain undercooling and the undercooling. Nucleation may even occur in the melt at a temperature higher than the liquidus, corresponding to the increase in the atmospheric pressure. It has been reported that grain size was reduced when ultrasonic vibration was applied at temperatures higher than the liquidus temperature [3].

3. Ultrasonically induced dendrite fragmentation. The convection and shock waves incurred in the solidifying melt during ultrasonic vibration can promote dendrite fragmentation, which is caused by melting at a dendrite root, where solutes are highly segregated. The melting at a dendrite root may be the result of a local temperature increase. The diffusion of solutes away 
from the dendrite roots would lead to a reduction of the solute concentration and increase in the local melting temperature. The effect would also lead to melting at the dendrite roots. Stirring can also promote dendrite fragmentation, since it produces local temperature variations and promotes diffusion of solutes in the liquid. Like mechanical stirring, ultrasonic vibration also stirs the melt and should promote dendrite fragmentation. Furthermore, the local pressure fluctuations described by Eqs. (3.1) and (3.2) should also lead to fluctuations in the melting temperature. These fluctuations should aid in the melting of the dendrite roots. This will lead to a more homogeneous microstructure with smaller grain sizes.

\subsection{Project Objectives}

Project objectives included (a) obtaining a better understanding of the effect of ultrasonic energy on the degassing of liquid metals during melting and on microstructure modification during solidification and (b) development of unique approaches for producing ultrafine grains and novel microstructures during the solidification processing of alloys.

\subsection{Work Breakdown Structure}

The hypotheses for the project were that if acoustic energy were introduced into molten materials (aluminum and steel alloys), the microstructure of the as-cooled material would be modified. It was hoped that the modified microstructure would exhibit superior mechanical properties. The approach consisted of exposing molten metal specimens to ultrasonic vibration of a certain intensity, amplitude, and frequency, with a given exposure time. The following tasks were envisioned and carried out.

\section{Task 1. Experimental Apparatus}

In Task 1, an experimental apparatus would be designed and built for various ultrasonic processing methods. The critical feature of the experimental apparatus was to design an ultrasonic vibrator/metal injection assembly at the top or the bottom of the metal mold. The assembly would consist of an ultrasonic radiator or horn that injects ultrasonic energy into the molten metal, an ultrasonic transducer, and a ram that connects to a piston to push the semisolid billet out of the mold. The weight of the billet would vary from 250 to $2000 \mathrm{~g}$. A coating to protect the acoustic radiator from high-temperature molten metals would also be developed.

\section{Task 2. Degassing of Aluminum Alloy Melts}

In Task 2, degassing of aluminum alloys using ultrasonic energy would be demonstrated. The experimental apparatus assembled in Task 1 would be used to study the degassing of aluminum alloy melts. The efficacy of degassing would be measured by metallography (effect on gas porosity), density measurements, and Leco hydrogen analysis. Based on the results, analytic forms for the application of ultrasonic degassing to large melts would be developed.

\section{Task 3. Thermodynamic Simulation of the Solid Fraction Verses Temperature Curves}

Task 3 involved thermodynamic simulation using the Scheil model to determine the solid fraction vs temperature curves of the aluminum alloys of interest (A356, A354, 319, 6061, 6063, and 3004) and a steel alloy, 4340 steel. The simulation would assume local equilibrium at the solid-liquid interface, no diffusion in the growing solid, and complete mixing in the liquid. The relationship to be developed between solid fraction and temperature would be used to determine the mechanisms which govern the formation of small spherical grains. 


\section{Task 4. Solidification of Alloys in an Acoustic Field}

In this task, the objective was to demonstrate grain refinement of aluminum alloys using ultrasonic energy. A parametric study would be carried out by varying the acoustic power, the frequency, the processing time, the casting temperature, and the cooling rate of the ingot.

\section{Task 5. Characterization of Solidification Microstructures}

In this task, specimens solidified under the influence of ultrasonic energy would be sectioned for characterization. Grain morphology, grain size, and size distribution would be measured. The measured results would be correlated with parameters such as ultrasonic frequency and power, the solid fraction at which the ultrasonic energy is applied, the temperature at which the melt is cast, and the cooling rates of the melt.

Task 6. Determination of the Fundamental Mechanisms during Ultrasonic Processing In Task 6, ultrasonic energy would be injected into various solid fractions of the solidifying alloy and grain refinement and spherical grain formation would be evaluated.

\section{Task 7. Industrial Applications of Results}

In Task 7 parameters for industrial applications of ultrasonic processing-including methods for introducing ultrasonic energy into the melt, variation of the applied amplitude and the intensity of ultrasonic vibrations, and the ultrasonic exposure time, specimen cooling rates, and specimen casting temperature-would be determined.

\section{Task 8. Reports and Publications}

In this task of the project, publications would include technical papers in journals, quarterly reports, annual review presentations, and a final report. 



\section{Experimental Methodology}

\subsection{Materials}

The aluminum alloy A356 was used for the investigation of ultrasonic degassing of melts. This alloy is a commercial aluminum-silicon alloy used in the automotive, aerospace, and defense industries owing to its light weight, high strength, good corrosion resistance, and castability.

In the experiments on ultrasonically induced microstructure modification, the materials chosen were commercial 4340 steel and the aluminum alloys A356, A354, 319, 3004, 6061, and 6063. These alloys are widely used in the aerospace and automotive industries. A356, A354, 319 alloys are casting alloys with high aluminum-silicon content and varying copper content, while 3004, 6061, 6063 are widely used wrought alloys.. The compositions of these materials are provided in Tables 4.1 and 4.2.

Table 4.1. Composition of aluminum alloys used in ultrasonics project

\begin{tabular}{|c|c|c|c|c|c|c|c|c|c|c|}
\hline Alloy & $\mathrm{Si}$ & $\mathrm{Fe}$ & $\mathrm{Cu}$ & Mn & Mg & $\mathrm{Cr}$ & $\mathrm{Zn}$ & $\mathrm{Ti}$ & $\mathrm{Ni}$ & Al \\
\hline A356 & 7 & 0.1 & 0.15 & 0.08 & 0.4 & - & 0.08 & 0.15 & - & $91-93$ \\
\hline A354 & $\begin{array}{l}8.6- \\
9.4\end{array}$ & 0.15 & $1.6-2$ & 0.1 & 0.5 & - & 0.1 & 0.2 & - & $87-89$ \\
\hline 319 & $\begin{array}{l}5.5- \\
6.5\end{array}$ & $<0.8$ & $3-4$ & $<0.5$ & $<0.1$ & - & 1 & 0.25 & 0.3 & $86-91$ \\
\hline 6061 & $\begin{array}{l}0.4- \\
0.8\end{array}$ & 0.7 & $\begin{array}{l}0.15- \\
0.40\end{array}$ & 0.15 & $0.8-1.2$ & $\begin{array}{l}0.04- \\
0.35\end{array}$ & 0.25 & 0.15 & - & $95-98$ \\
\hline 6063 & $\begin{array}{l}0.3- \\
0.6\end{array}$ & 0.35 & 0.10 & 0.10 & $0.45-0.9$ & 0.10 & 0.10 & 0.10 & - & $97-99$ \\
\hline
\end{tabular}

Table 4.2. Composition of 4340 steel

\begin{tabular}{ccccccccc}
\hline $\mathbf{F e}$ & $\mathbf{S i}$ & $\mathbf{C}$ & $\mathbf{M n}$ & $\mathbf{N i}$ & $\mathbf{C r}$ & $\mathbf{M o}$ & $\mathbf{S}$ & $\mathbf{P}$ \\
\hline 96 & 0.23 & $0.37-0.43$ & 0.7 & 1.83 & $0.7-0.9$ & $0.2-0.3$ & $<0.04$ & $<0.035$ \\
\hline
\end{tabular}

\subsection{Experimental Setup}

An ultrasonic unit with high-power capacity was used to investigate the effect of the ultrasonic vibration on the solidification and degassing of the steel and aluminum alloys. This unit provides a $1500-\mathrm{W}$ electric power supply and consists of a $20-\mathrm{kHz}$ acoustic generator, an air-cooled converter made of piezoelectric lead zirconate titanate (PZT) crystals, a booster, a probe, and an acoustic radiator made of the titanium alloy Ti-6Al-4V. The ultrasonic amplitude can be continuously adjusted from 30 to $100 \%$ or $81 \mu \mathrm{m}$, which is the maximum amplitude of the unit.

Figure 4.1 shows the setup for experiments when ultrasonic vibrations were introduced directly into the melt. A pneumatically operated device moved the acoustic radiator up or down. The time to preheat the extender and to dip it into the melt could be precisely controlled. 


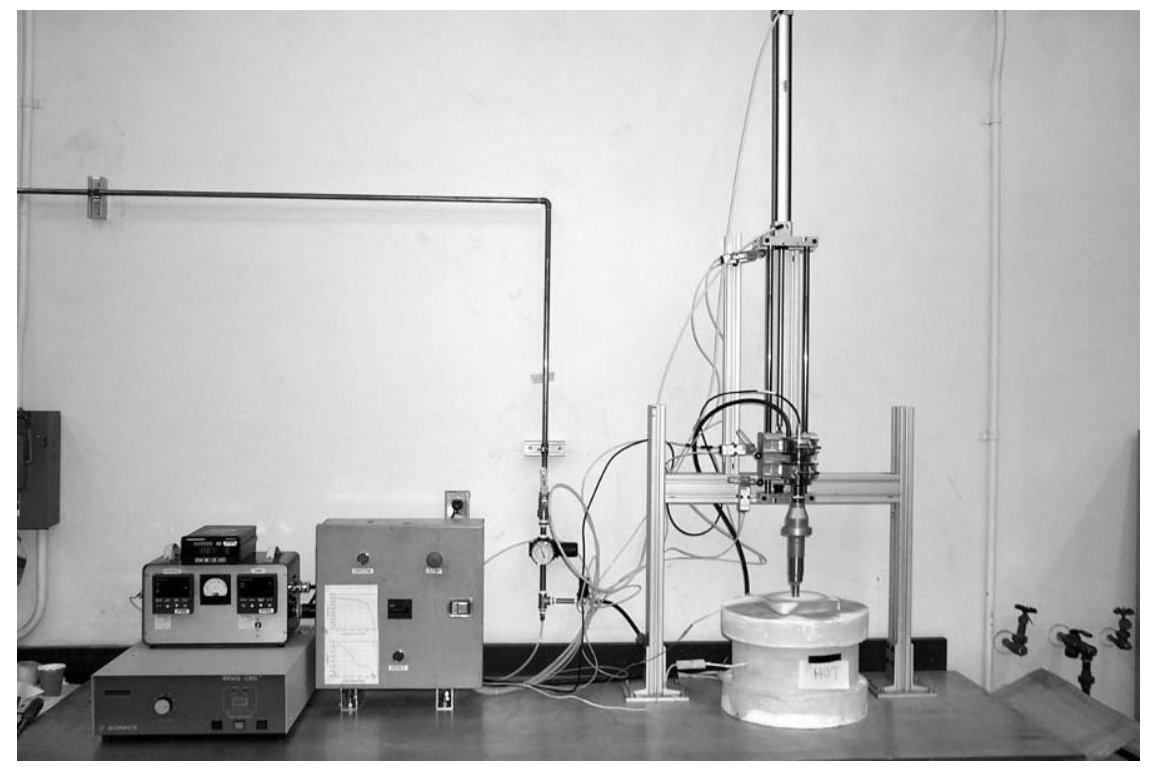

Fig. 4.1. Experimental apparatus for the ultrasonic vibrator/metal injection assembly at the top of the melts.

\subsection{Ultrasonic Degassing Experiments}

Ultrasonic degassing was conducted with the device shown in Fig. 4.1. In this process, ultrasound was injected from the top of the aluminum melt by using a cylindrical radiator made of the titanium alloy Ti-6Al-4V. The aluminum alloy was held in a graphite crucible and melted in the furnace. The temperature of the melt was controlled to within $\pm 10^{\circ} \mathrm{C}$. Three variables were investigated: ambient humidity, melt temperature, and melt or crucible size. The ambient humidity was varied from 40 to $60 \%$. Four melt temperatures $-620^{\circ} \mathrm{C}, 660^{\circ} \mathrm{C}, 700^{\circ} \mathrm{C}$, and $740^{\circ} \mathrm{C}-$ were tested. The weights of the melt were $0.2,0.6$, and $2 \mathrm{~kg}$, respectively.

A reduced-pressure test (RPT) was employed to determine the porosity level of the cast. Molten alloy $(-120 \mathrm{~g})$ was poured into a preheated thin-walled iron cup and allowed to solidify under a reduced pressure of $50 \mathrm{~mm} \mathrm{Hg}$ (i.e., a vacuum of $28 \mathrm{in}$. $\mathrm{Hg}$ ). Pressures of $50-100 \mathrm{~mm}$ are usually used for RPT [6,7]. The RPT specimens were sectioned in the middle vertically and were polished to reveal the extent of the hydrogen porosity. The densities of the RPT specimens were measured by the apparent density measurement method [8]. The specimen was weighed in air and in water. The density, $D$, of the specimen is given in the following equation:

$$
D=\frac{W_{a}}{W_{a}-W_{w}},
$$

where $W_{\mathrm{a}}$ and $W_{\mathrm{w}}$ are the weights of the specimen by air and water, respectively.

\subsection{Ultrasonic Grain Refinement Experiments}

Two types of ultrasonic grain refinement experiments were carried out: isothermal processing and intermittent processing. Before ultrasonic processing, the $\mathrm{A} 356$ alloy was melted at $614^{\circ} \mathrm{C}$ and then raised to a temperature of $650^{\circ} \mathrm{C}$; meanwhile, the ultrasonic radiator was preheated to this temperature and then dipped into the melt. With the ultrasonic radiator inserted into the melt, the melt 
was kept at this temperature for $30 \mathrm{~min}$. For the isothermal processing, the melt was then cooled to a temperature near the liquidus $\left(614\right.$ or $\left.610^{\circ} \mathrm{C}\right)$ and subjected to ultrasonic vibration for a given time (5, 10, and 20 seconds (s)). After the processing, the melt was poured into either a metal mold or a claygraphite mold to solidify at two different cooling rates. For the intermittent processing, the cover of the furnace was removed to cool down the melt rapidly. While the temperature was decreasing, the melt was subjected to ultrasonic vibration for specified periods of time $(5,10$, and $20 \mathrm{~s})$ at decreasing temperature steps of $\left(614,610,605,600,595,590,585,580\right.$, and $\left.575^{\circ} \mathrm{C}\right)$, or it was ultrasonically vibrated continuously from 614 to $575^{\circ} \mathrm{C}$. The ultrasonic system did not function when the melt reached $574^{\circ} \mathrm{C}$ because the solid fraction had become too high.

Another method of application was investigated by vibrating the solid part of the solidifying specimen. In this technique, ingots of the test material were melted in a 10-kg-capacity SiC crucible using an electrical resistance furnace. The melt temperature was kept at a temperature $\sim 50-150^{\circ} \mathrm{C}$ higher than the liquidus temperature of the alloy to allow for the complete dissolution of all elements during melting. The molten alloy was then poured into a copper or graphite mold that held up to 250 $\mathrm{g}$ of molten aluminum or $1 \mathrm{~kg}$ of steel alloy 4340 at various pouring temperatures. The ultrasonic vibration was started just before the melt was poured into the copper mold. In order to obtain the optimum condition for grain refinement, parameters such as vibration amplitude, vibration time, and pouring temperature of the melt were controlled. During processing, the actual power output varied from 5 to $75 \%$ of the nominal power capacity of the ultrasonic unit.

\subsection{Quantitative Metallography}

Quantitative metallographic analyses were conducted on aluminum-rich primary alpha grains and eutectic silicon particles using an image analysis software, Image-Pro Plus (version 5.0). For the characterization of primary alpha grains, the average area, particle size, and roundness were also measured. The quantitative characterization of eutectic silicon included particle area, length, and roundness. Scanning electron microscopy (SEM) was used to observe the three-dimensional eutectic silicon morphology of the specimens, which were deep-etched using a $0.5 \%$ HF-water solution.

ASTM standard methods were used to determine grain size. Two parameters were measured to quantitatively characterize the primary aluminum grain structure: the average grain size $(D)$ and the roundness $(\mathrm{Rn})$ of the grains. The average particle size is defined as

$$
D=2 \times \sqrt{\frac{A}{\pi}},
$$

where $A$ is the area of a grain. The average grain size and its standard deviation were obtained based on measurements of more than 2000 grains.

The roundness $(\mathrm{Rn})$ was defined as

$$
R n=\frac{4 \pi A}{P^{2}}
$$

where $P$ is the perimeter of the particle. The maximum value for roundness-when the particle is a perfect sphere-is 1 . Particles become less spherical at lower roundness values. 



\section{Results and Discussion}

\subsection{Coating Test to Protect Ultrasonic Radiator at High Temperature}

In order to protect the titanium ultrasonic radiator from reaction with molten metals, experiments were carried out to test the effectiveness of various coatings. A titanium horn was coated with various coatings, placed in molten bismuth, and subjected to continuous (not pulsed) ultrasonic power varying from 0 to $750 \mathrm{~W}$. Molten bismuth was used because of its low melting point. The horn was then examined for coating fractures. The results are shown in Figs. 5.1-5.5. The interface of the titanium horn and the molten metal has metallurgical bonding when no coating was used. The coatings of oxide, graphite, and boron nitride offered some protection. However, the bonding of the radiator to these coatings was not enough to resist the thermal shock and acoustic vibrations. Because only ZGuard worked well in the process, it was decided to use this product as a protective coating on the titanium horn.
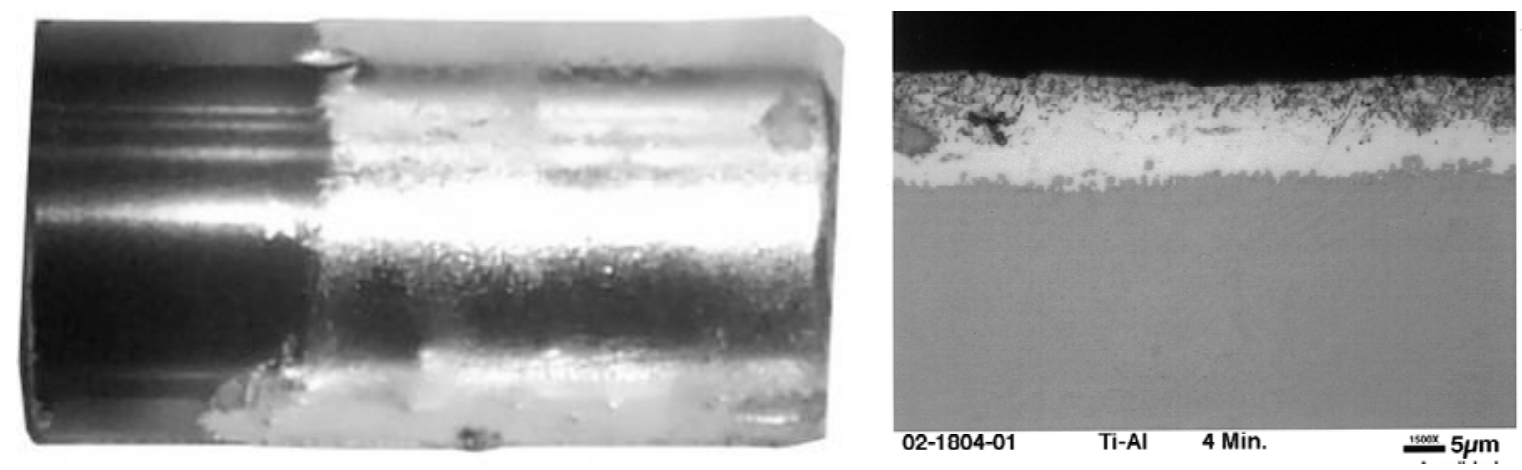

Fig. 5.1. Radiator surface with no coating. Metallurgical bonding can be seen on the surface that had been in contact with the melt. This approach resulted in significant degradation of the ultrasonic radiator..

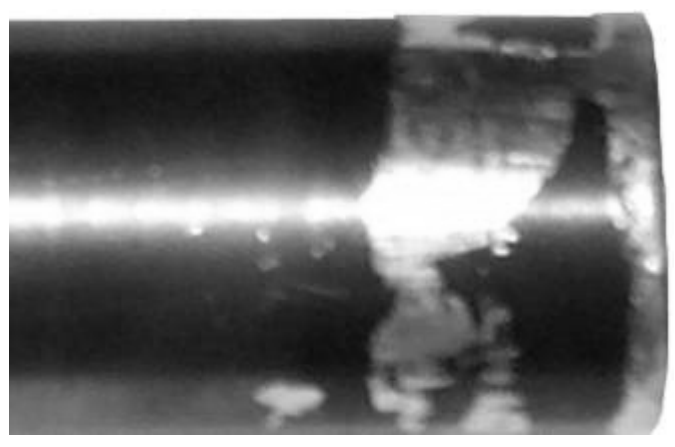

Fig. 5.2. Radiator surface with oxide layer. Metallurgical bonding can be seen on most of the contacting area. The protection was not sufficient.

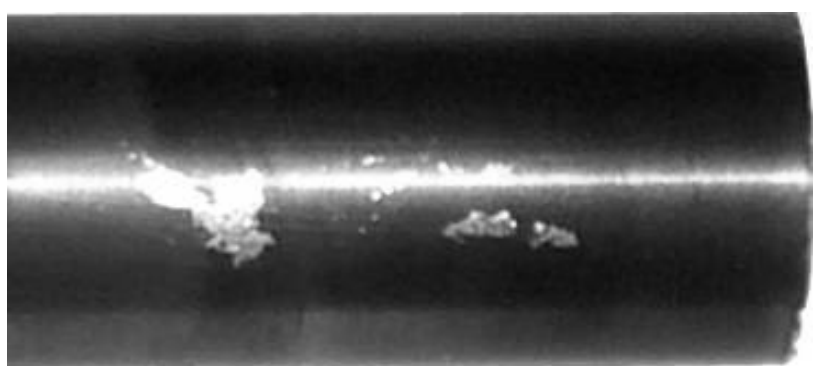

Fig. 5.3. Radiator surface with graphite coating. Some metallurgical bonding can still be observed. The protection was still not sufficient. 


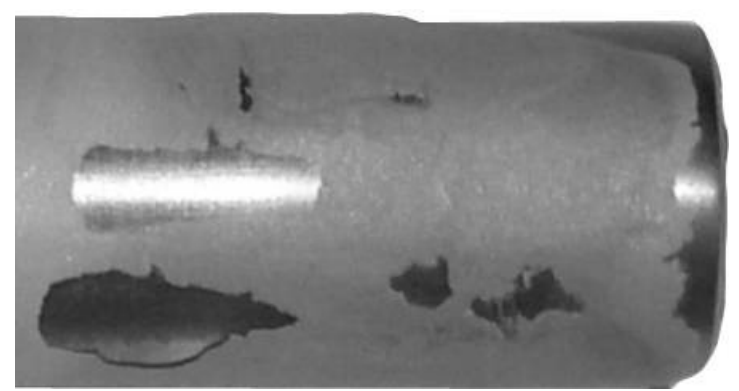

Fig. 5.4. Radiator surface with boron nitride coating. While no metallurgical bonding was observed, the bonding between the coating and radiator surface was not strong enough.

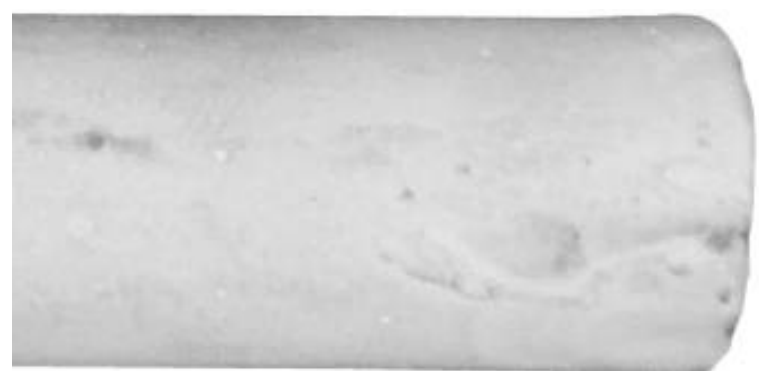

Fig. 5.5. Radiator surface with Z-Guard coating. No metallurgical bonding was observed. The bonding between the coating and radiator surface was excellent.

\subsection{Degassing of A356 Alloy}

Ultrasonic degassing was tested with different volumes of aluminum melt at various processing temperatures and durations. The efficiency of degassing was evaluated by density measurements of reduced-pressure specimens (RPT). Experimental results indicate that a steady-state hydrogen concentration can be obtained within a few minutes of ultrasonic vibration, regardless of the initial hydrogen concentration in the melt. The dynamics of hydrogen evolution as a function of processing time, melt temperature, and initial hydrogen concentrations were investigated. Results show that ultrasonic vibration can be used to reduce porosity formation in aluminum alloys, as shown in Figs. 5.6-5.9.

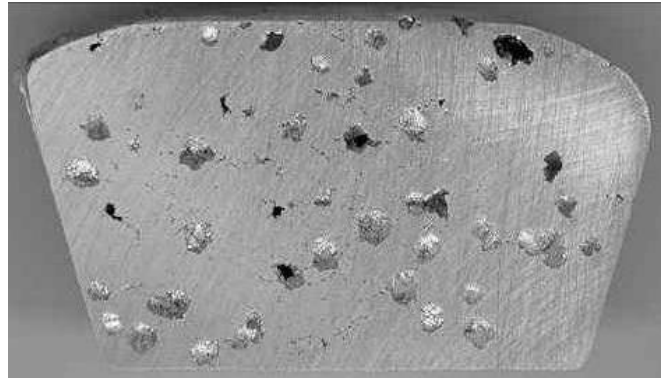

(a) 0 min

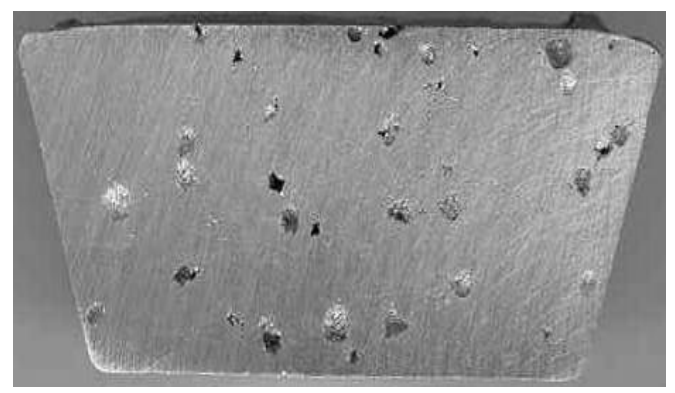

(c) 2 min

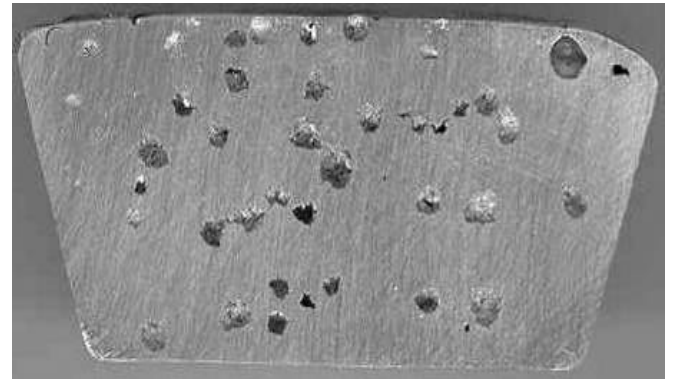

(b) 1 min

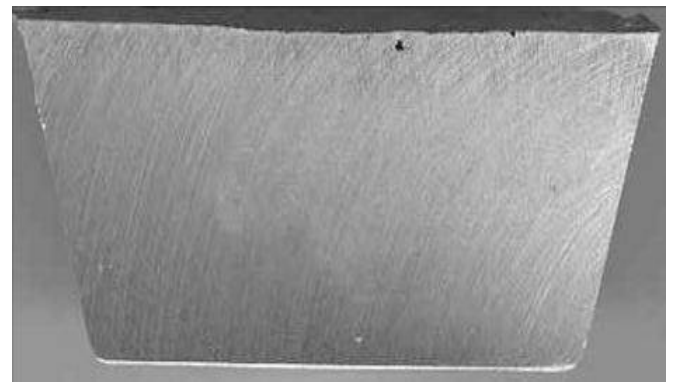

(d) $4 \mathrm{~min}$

Fig. 5.6. Porosity in RPT specimens made from the melt and subjected to various ultrasonic processing times. The processing temperature was $740^{\circ} \mathrm{C}$, and the humidity was $60 \%$. With increasing processing time, the porosity decreased significantly. 


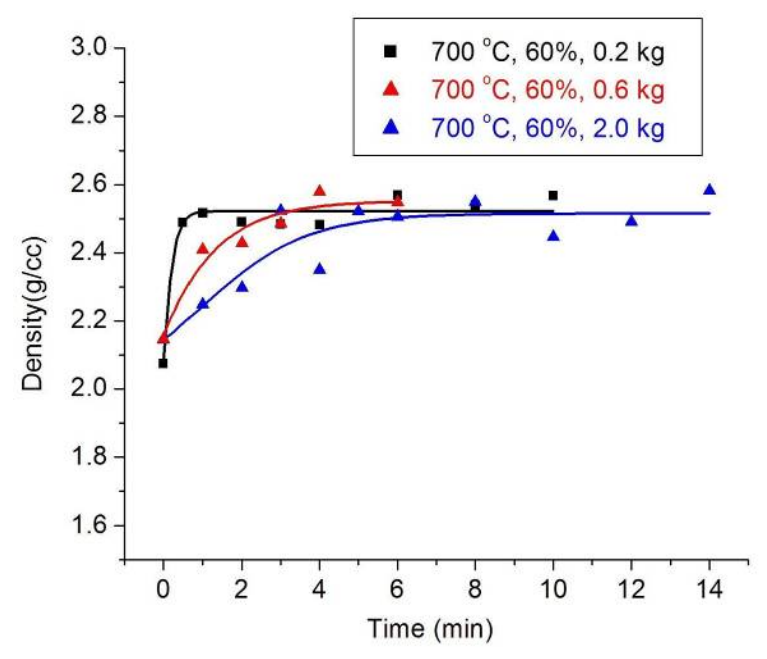

Fig. 5.7. Effect of processing time on porosity for varying melt sizes. Degassing can be accomplished within 1-2 min of ultrasonic vibrations.

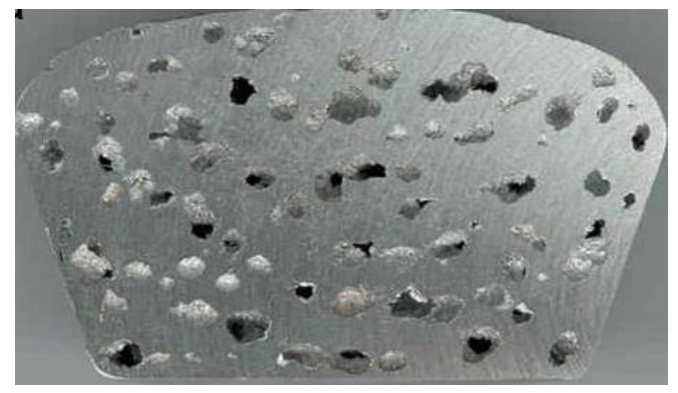

(a) 0 min

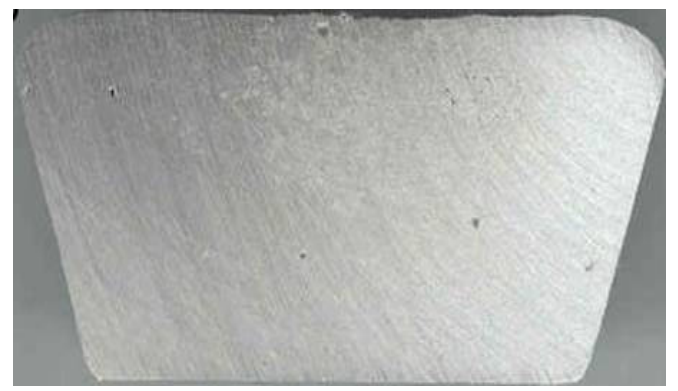

(b) 1 min

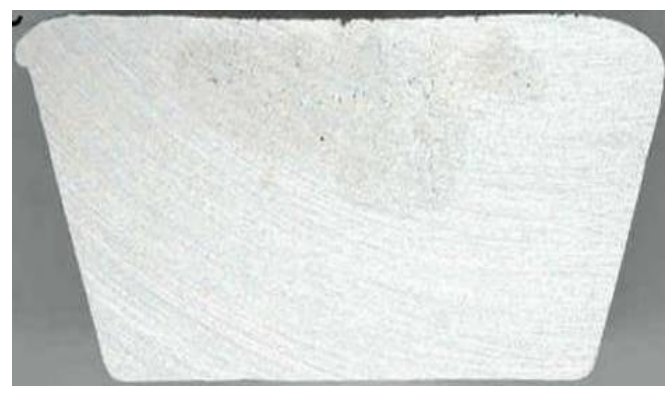

(c) 4 min

Fig. 5.8. RPT specimens at various ultrasonic processing times. The melt was processed at $740^{\circ} \mathrm{C}$ at a humidity of $60 \%$. 


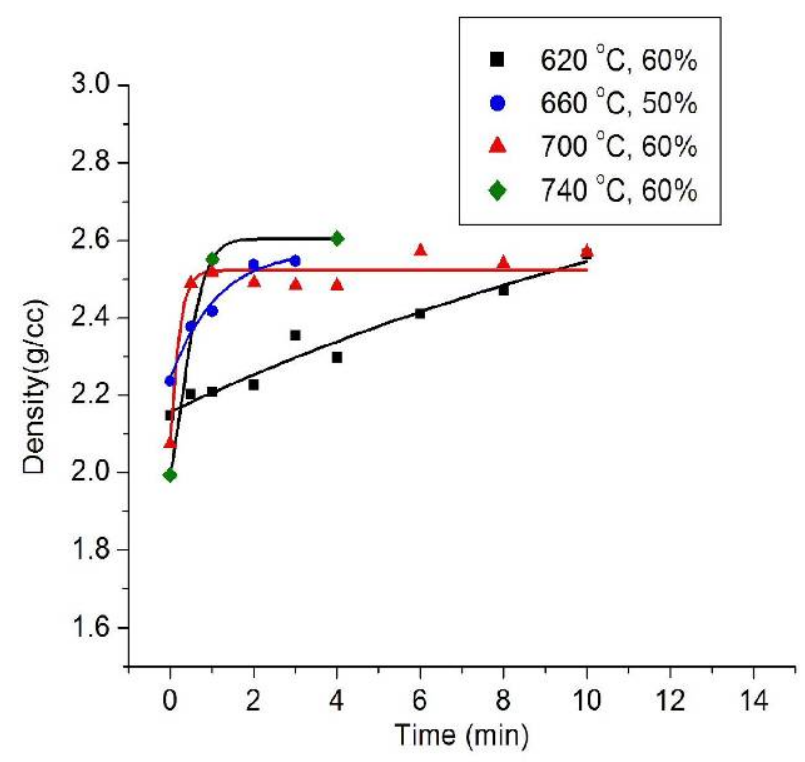

Fig. 5.9. Measured density of the RPT specimen as a function of ultrasonic processing time in melt at different processing temperatures.

\subsection{Thermodynamic Simulations}

Thermodynamic simulations based on the Scheil model were carried out to determine the solid fraction vs temperature curves for aluminum alloys A356, A354, 319, 6061, 6063, and 3004, and for 4340 steel, with the compositions shown in Tables 4.1 and 4.2. The simulations assumed local equilibrium at the solid/liquid interface, no diffusion in the growing solid, and complete mixing in the liquid. The results are shown in Fig. 5.10.

The commercial A356 alloy was used. Thermodynamic simulation results show that the liquidus temperature of this alloy is $614^{\circ} \mathrm{C}$, and the solidus temperature is $554^{\circ} \mathrm{C}$ (Fig. 5.10a). This analysis was performed in order to determine the proper temperature at which to introduce ultrasonic energy. 


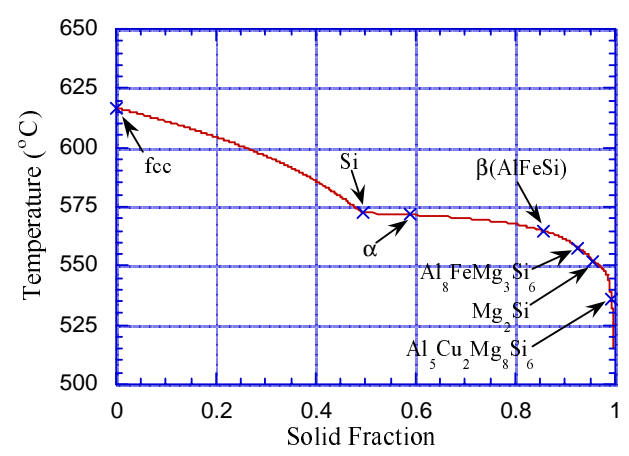

(a) A356 alloy

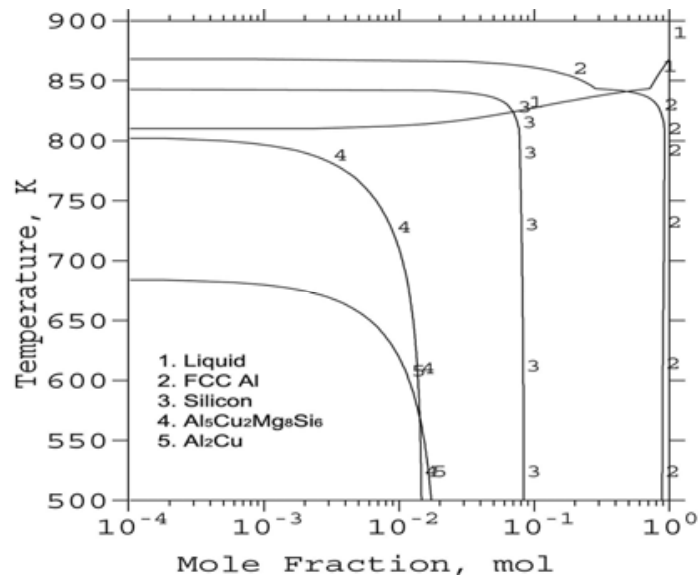

(c) A354 alloy

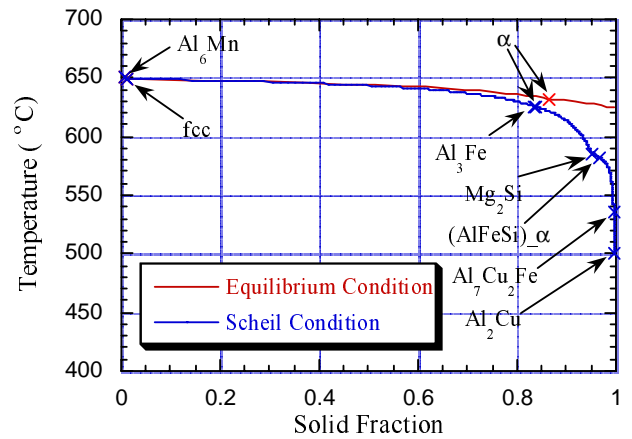

(b) 3004 alloy

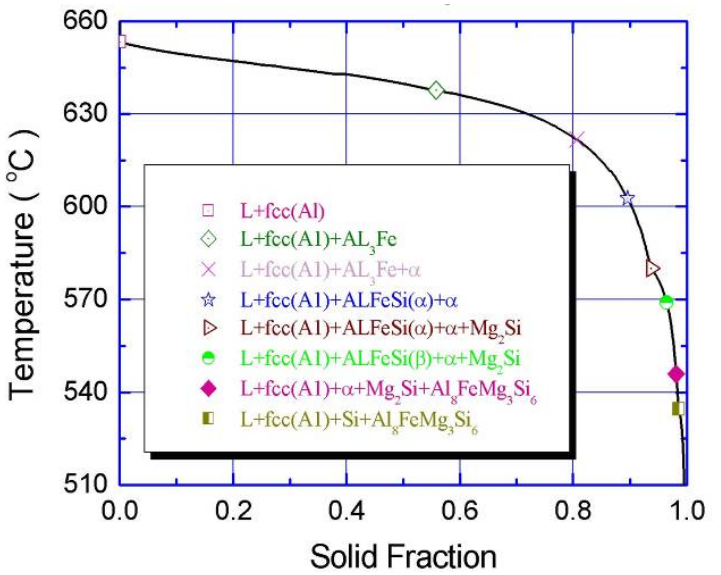

(d) 6061 alloy

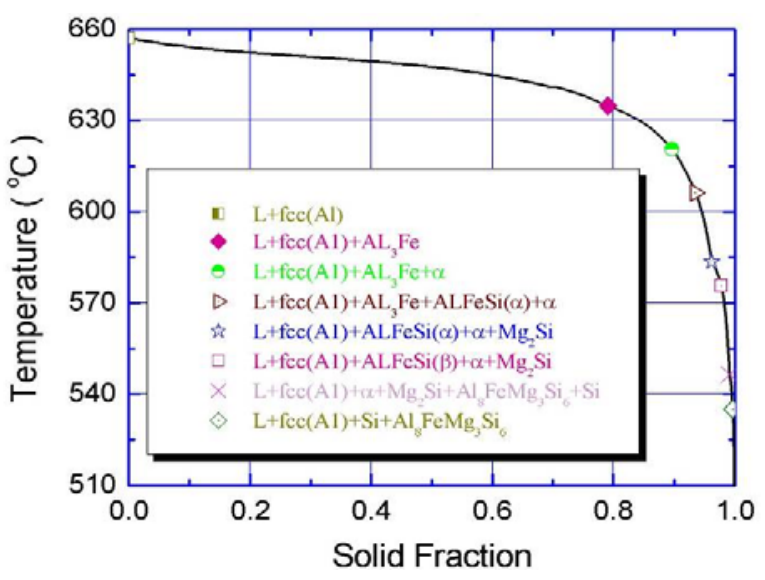

(e) 6063 alloy

Fig. 5.10. Temperature vs solid fraction curve for selected aluminum alloys. 


\subsection{Grain Refinement of Aluminum Alloys}

\subsubsection{A356 Alloy}

The effect of intermittent ultrasonic processing was investigated. The alloy specimens were treated under the same conditions, except that the control specimen was allowed to solidify without ultrasonic vibration, and the other specimen was solidified with $5 \mathrm{~s}$ of intermittent ultrasonic vibration. The results are illustrated in Fig. 5.11. Fine globular grains were obtained in the ultrasonically treated specimen.

The alloy was then treated isothermally at various solid fractions using ultrasonic processing, with one group cast in a graphite mold and the other in a metal mold. The results, shown in Figs. 5.125.13, indicate that it is difficult to obtain globular grains if the specimens are treated at isothermal temperatures in the mushy zone. Applying ultrasonic vibration to the alloy close to its liquidus temperatures, following by rapid cooling, resulted in fine globular grains.

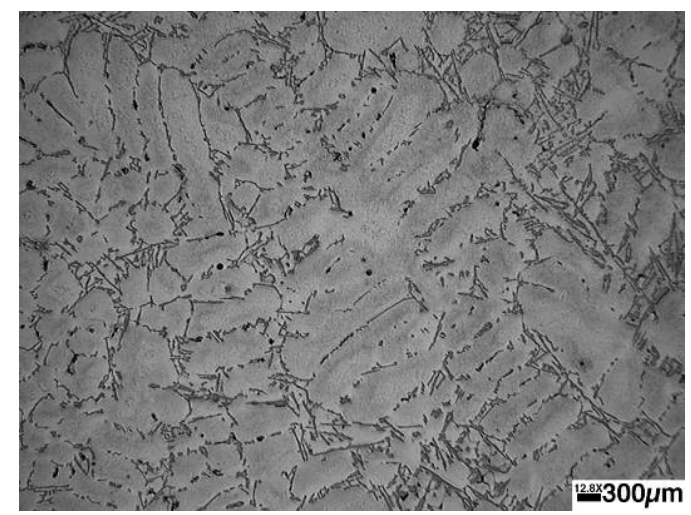

(a) Control

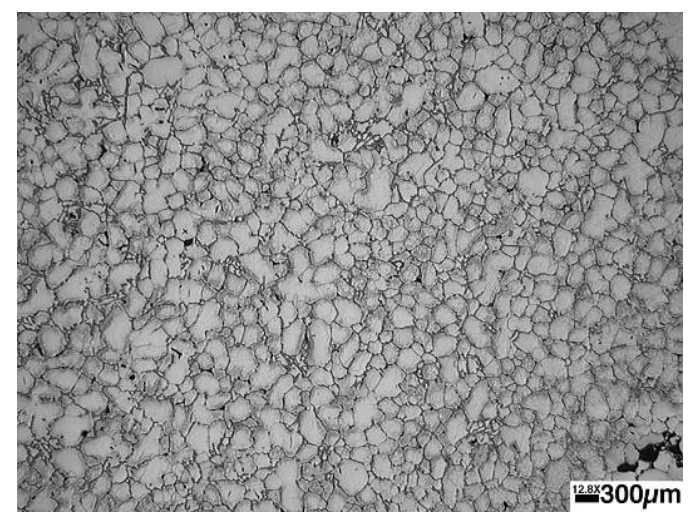

(b) 5 seconds

Fig. 5.11. Microstructure of A356 specimens without (a) and with (b) intermittent ultrasonic processing at different exposure times. The ultrasonically modified material has a much improved and finer globular microstructure. 


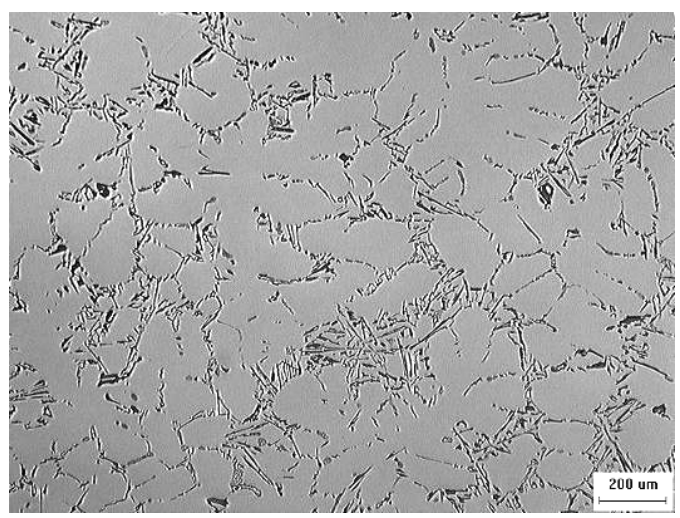

(a) No vibration

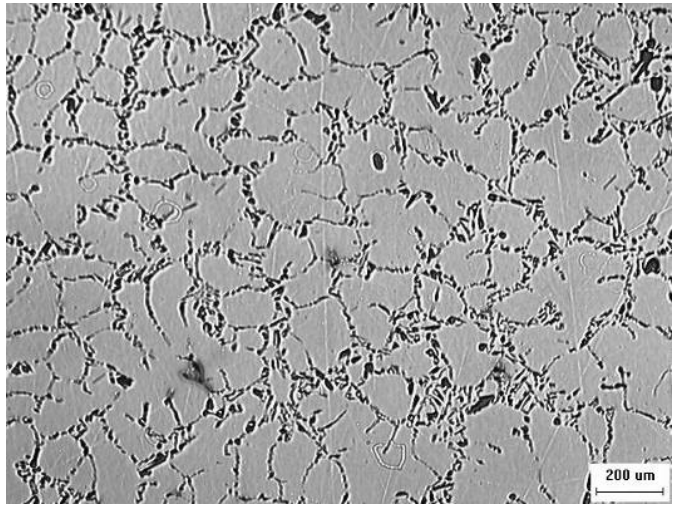

(b) $614^{\circ} \mathrm{C}, 5 \mathrm{~s}$

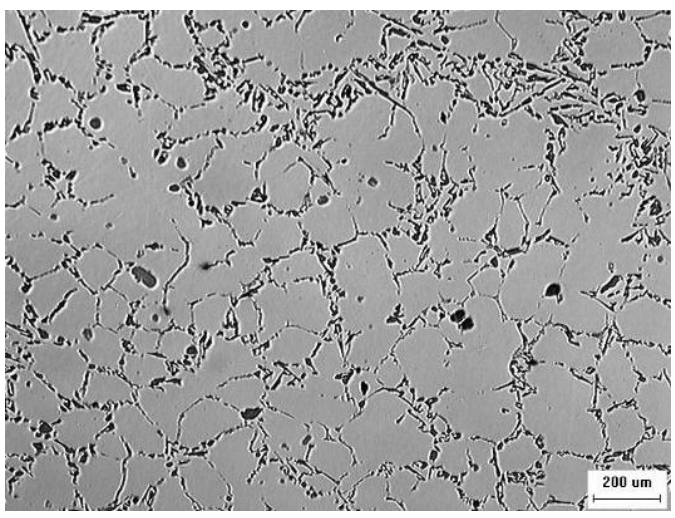

(d) $610^{\circ} \mathrm{C}, 5 \mathrm{~s}$

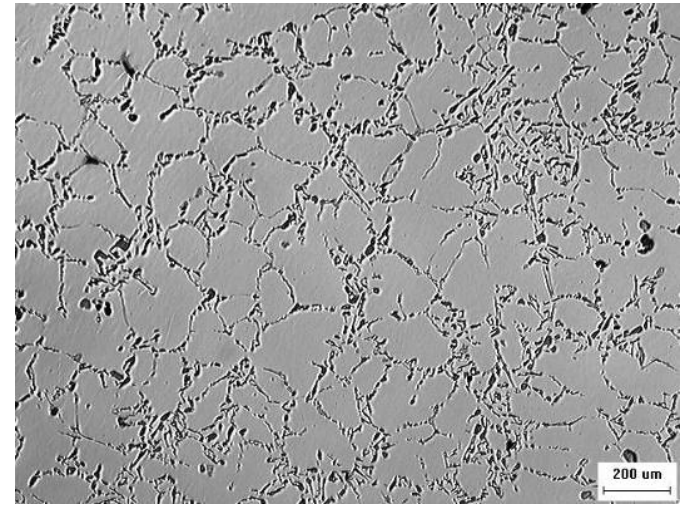

(c) $614^{\circ} \mathrm{C}, 20 \mathrm{~s}$

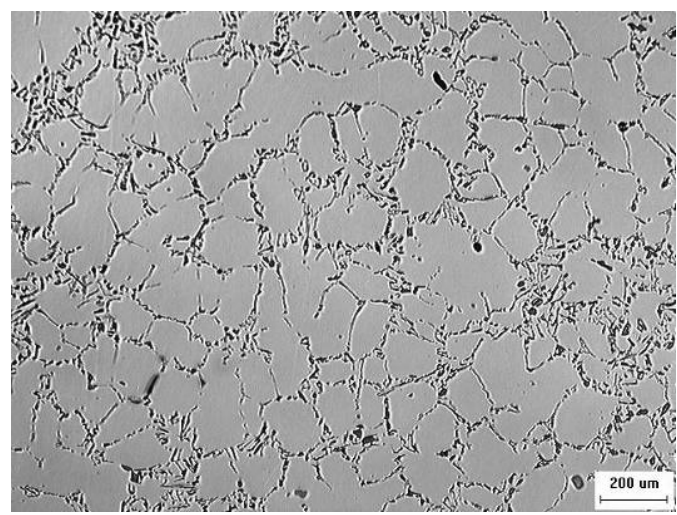

(e) $610^{\circ} \mathrm{C}, 20 \mathrm{~s}$

Fig. 5.12. Microstructure of $A 356$ specimens without and with isothermal ultrasonic processing at different temperatures and durations. Specimens were cooled in a graphite crucible. Results show that upon ultrasonic exposure, the dendrites were broken into much smaller grains, greatly improving the microstructure for improved properties and process yield. 


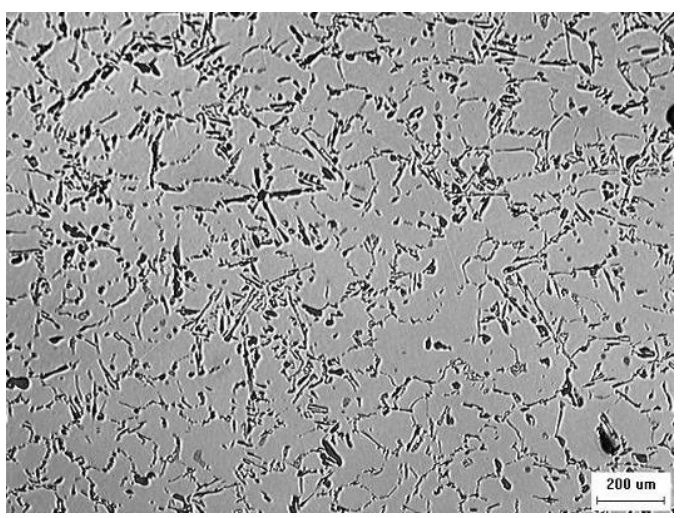

(a) No vibration

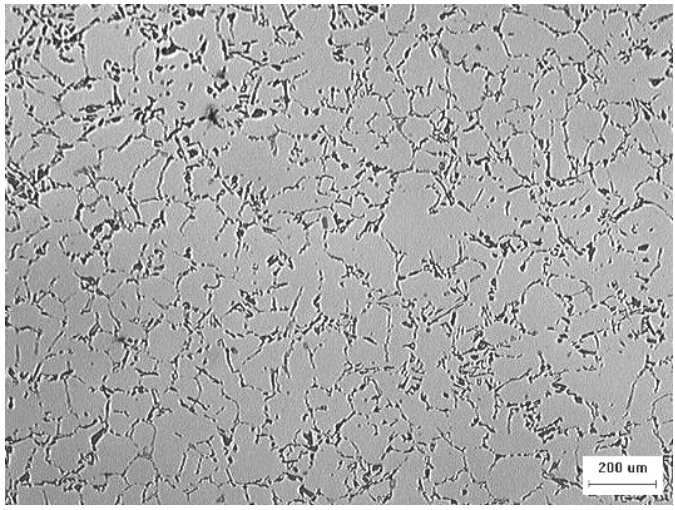

(c) $614^{\circ} \mathrm{C}, 20 \mathrm{~s}$

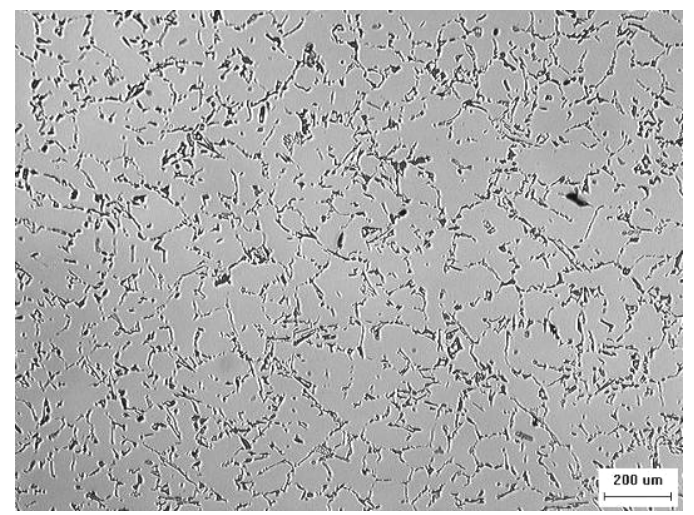

(b) $614^{\circ} \mathrm{C}, 5 \mathrm{~s}$

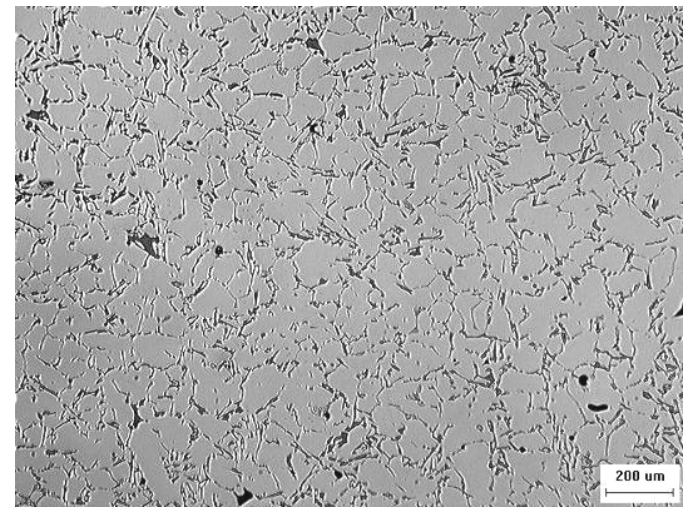

(d) $610^{\circ} \mathrm{C}, 5 \mathrm{~s}$

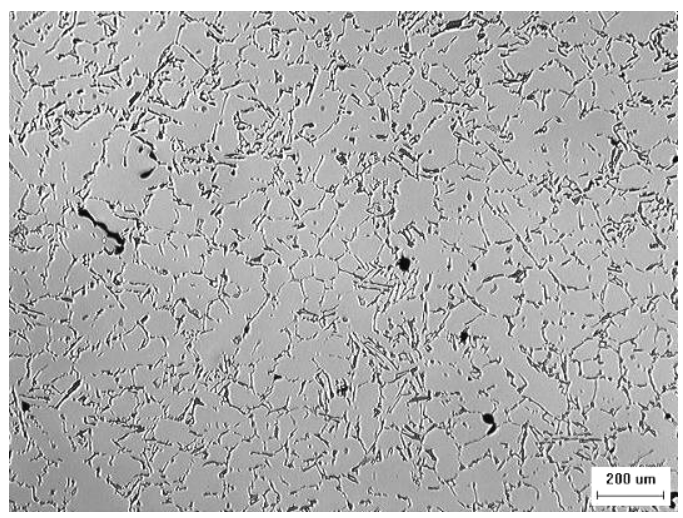

(e) $610^{\circ} \mathrm{C}, 20 \mathrm{~s}$

Fig. 5.13. Microstructure of A356 specimens without and with isothermal ultrasonic processing at different temperatures and durations. Specimens were cooled in a metal mold. Results are similar to those shown in Fig. 5.12, but with smaller grains due to the higher cooling rate in the metal mold than that in the clay graphite mold. 
The experiments that involved vibrating the solid part of the solidifying specimen* were performed under varied conditions, including different casting temperatures, vibrational amplitude, and vibration duration times. This work was focused on finding the optimum conditions for grain refinement via metal mold casting, anticipating an industrial application for the use of ultrasonic vibration in this area. Results shown in Fig. 5.14 indicate that the best grain refinement resulted from both high acoustic amplitude and low casting temperature-i.e., at an amplitude of $70 \%$ and a temperature of $620-630^{\circ} \mathrm{C}$. In the bulk, most grains possess a global shape and are $20-40 \mu \mathrm{m}$ in diameter. Grains smaller than $10 \mu \mathrm{m}$ were obtained in the area near the vibration source. It is evident that upon ultrasonic processing at these favored conditions, the dendrites were completely removed, resulting in an extraordinary grain refinement and microstructure modification unparalleled with traditional grain refinement methods. This should lead to a more energy-efficient process.

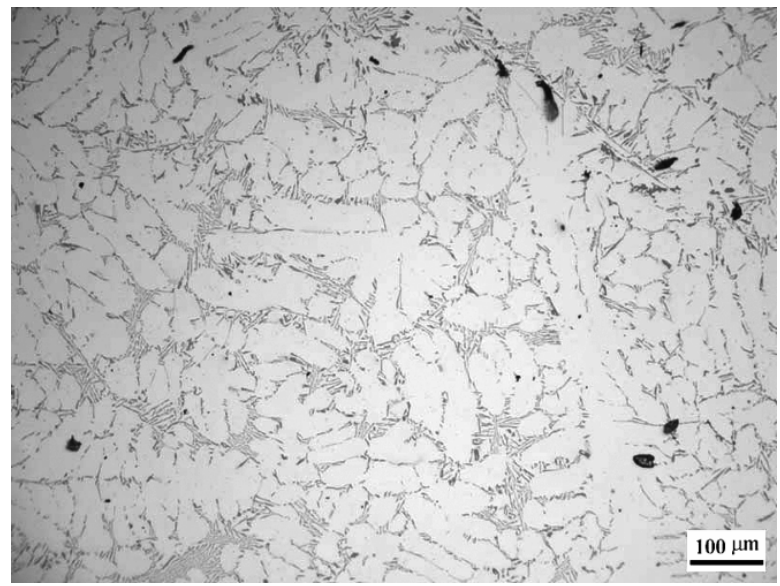

(a) Without ultrasonic vibration; casting temperature $630^{\circ} \mathrm{C}$

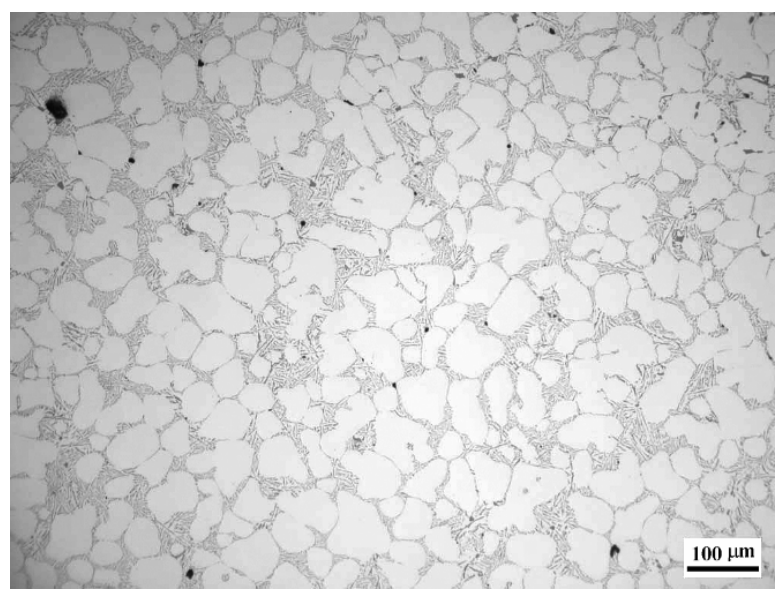

(c) With ultrasonic vibration; $70 \%$ amplitude, $620^{\circ} \mathrm{C}$, near the middle of the ingot

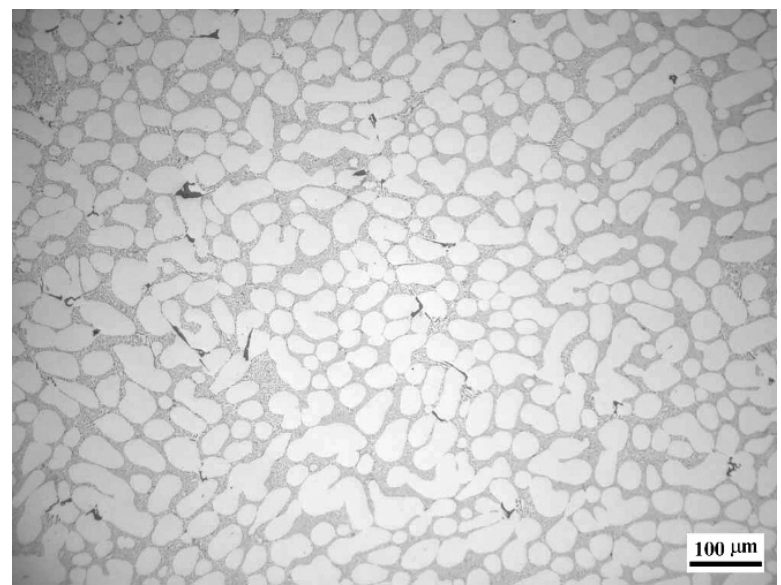

(b) With ultrasonic vibration; $70 \%$ amplitude, $620^{\circ} \mathrm{C}$

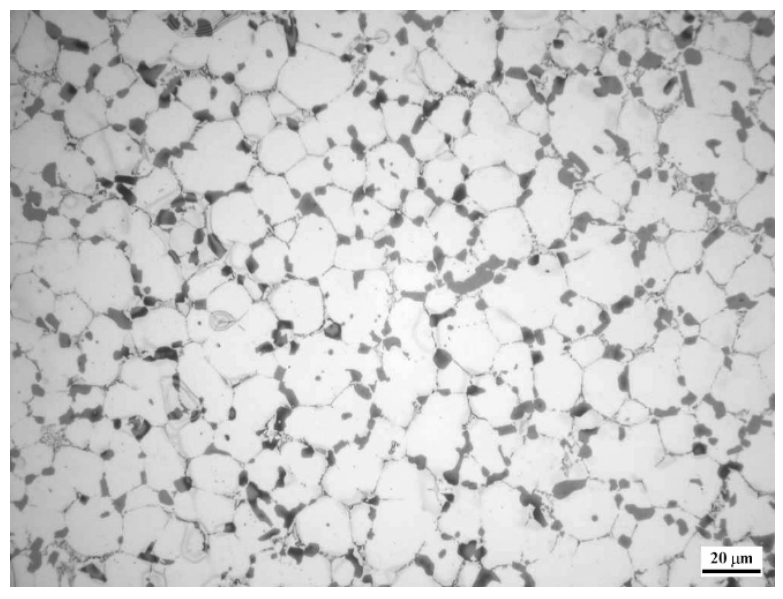

(d) With ultrasonic vibration; $70 \%$ amplitude, $620^{\circ} \mathrm{C}$, near the acoustic radiator

Fig. 5.14. Microstructure of A356 specimens without and with ultrasonic processing applied to the solid part of the solidifying specimen and then cooled in a metal mold. Upon ultrasonic processing, very fine globular grains were obtained. In the area near the ultrasonic radiator, superfine grains along with a modified silicon phase were obtained.

*Patentable information. 


\subsubsection{Alloy}

Thermodynamic simulations indicated that the melting point of aluminum alloy 6061 is $\sim 653^{\circ} \mathrm{C}$. The experiments that involved ultrasonic processing of the solid part of the solidifying specimen were performed under a number of conditions, such as varying the casting temperature from 660 to $720^{\circ} \mathrm{C}$. The vibrational amplitude was $100 \%$, and vibration duration time was $60 \mathrm{~s}$. Results are shown in Fig. 5.15. It is obvious that ultrasonic vibration is very effective in the grain refinement of this alloy. Dendrites do not appear on the specimen treated with ultrasonic vibrations.

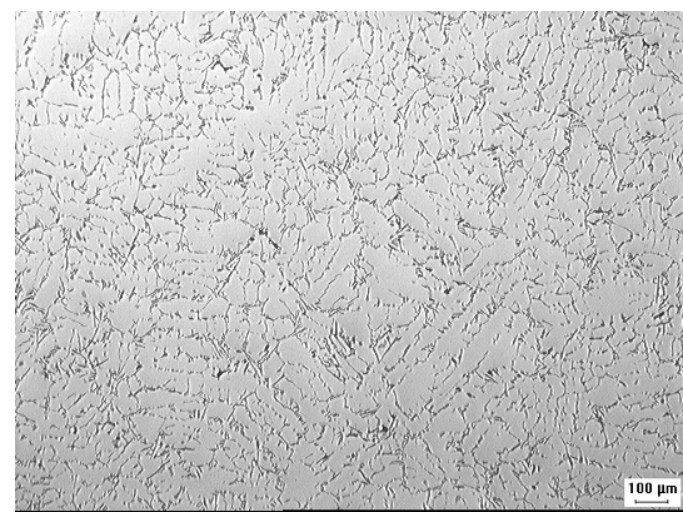

(a) No vibration; casting temperature, $690^{\circ} \mathrm{C}$

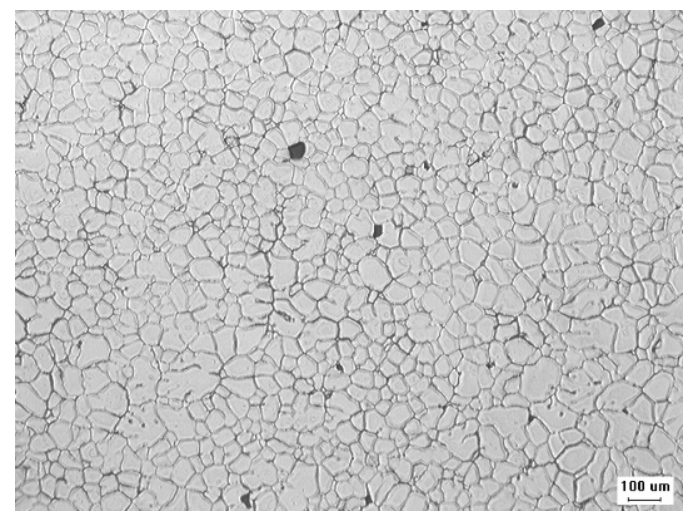

(b) With vibration; casting temperature, $700^{\circ} \mathrm{C}$

Fig. 5.15. Microstructure of 6061 alloy without and with ultrasonic vibration. Upon ultrasonic processing, fully developed dendrites were completely removed and fine globular grains were obtained. This is expected to lead to improved properties and improved mechanical processing of materials.

\subsubsection{Alloy}

Thermodynamic simulation indicated that the melting point of this alloy is $\sim 657^{\circ} \mathrm{C}$. The experiments to vibrate the solid part of solidifying specimens were performed under a number of conditions, such as varying the casting temperature from 670 to $730^{\circ} \mathrm{C}$. The vibration amplitude was $100 \%$, and vibration duration time was $60 \mathrm{~s}$. Results are shown in Fig. 5.16. Dendrites are fully developed on the untreated specimen. However, on the two specimens treated ultrasonically, dendrites do not appear and the microstructure seems to be fine and globular. It is obvious that ultrasonic vibration is very effective in the grain refinement of this alloy. 


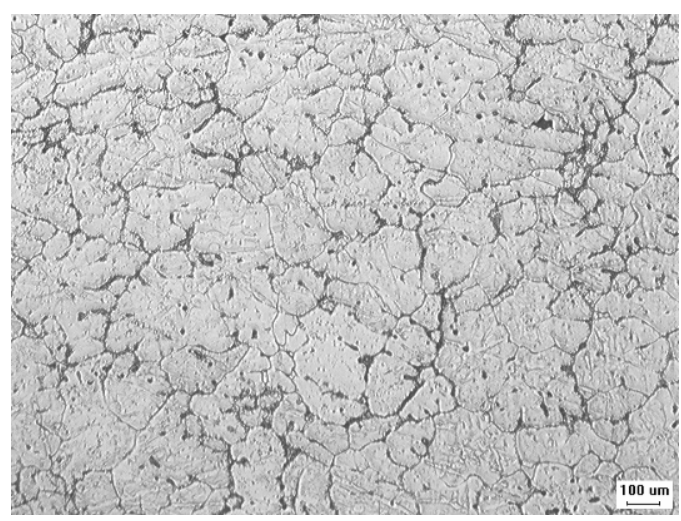

(a) No vibration; casting temperature, $690^{\circ} \mathrm{C}$

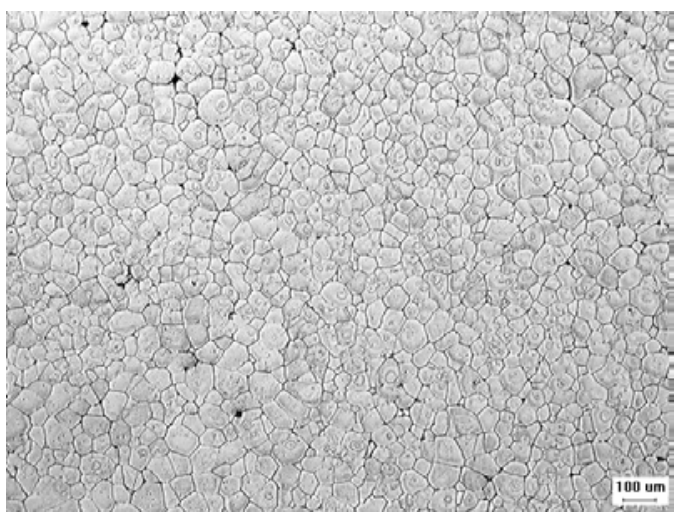

(b) With vibration; casting temperature, $700^{\circ} \mathrm{C}$

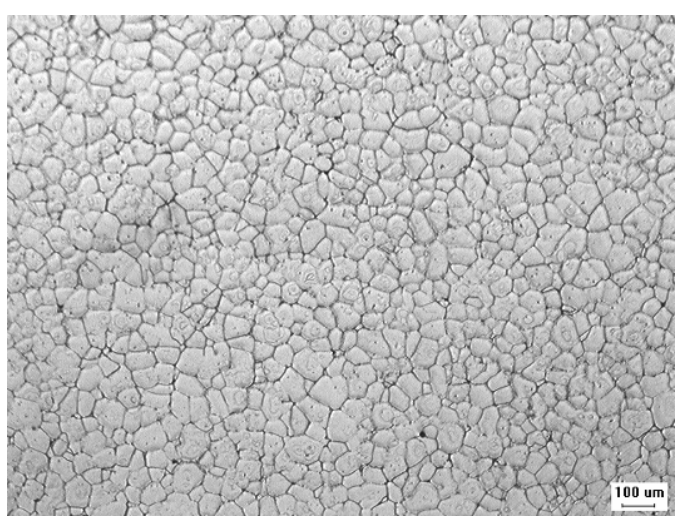

(c) With vibration; casting temperature, $730^{\circ} \mathrm{C}$

Fig. 5.16. Microstructure of 6063 alloy without and with ultrasonic vibration. Again, ultrasonic processing was proven to be efficient in obtaining small, globular grains in this aluminum-siliconmagnesium wrought alloy.

\subsubsection{Alloy}

Aluminum alloy 319 was cast either in copper or in graphite molds under ultrasonic vibration at different casting temperatures. Alloy 319 is of interest commercially for making automotive components; however, grain refinement is difficult to achieve with this material (the normal grain size is in millimeters). Experiments were conducted in order to investigate grain refinement via ultrasonic processing. The applied ultrasonic amplitude was set at 100\%, and the processing time was $60 \mathrm{~s}$. Figure 5.17 shows the measured cooling curve of 319 alloy without ultrasonic vibration. Figure 5.18 shows an untreated specimen and ultrasonically treated specimens cast at different temperatures. As the figure indicates, ultrasonic processing greatly improved the microstructure of the alloy. The grain size decreased from $>1 \mathrm{~mm}$ (without vibration) to $<20 \mu \mathrm{m}$, and even to $<10 \mu \mathrm{m}$ under some conditions. 


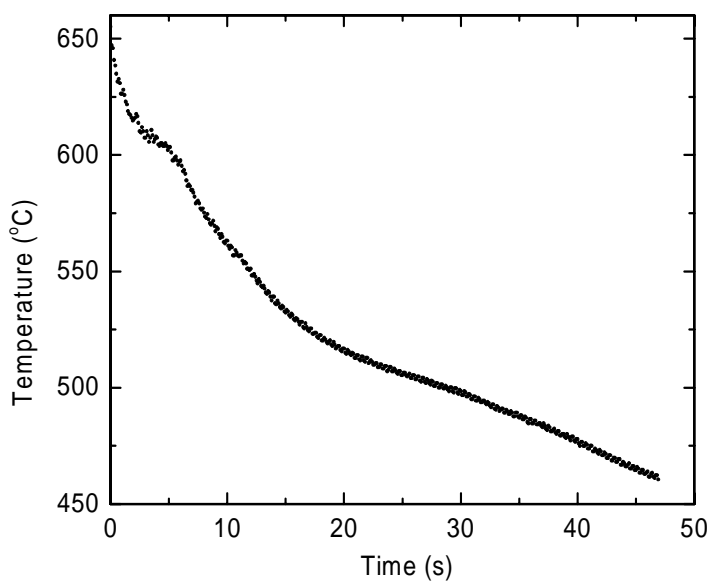

Fig. 5.17. Measured cooling curve of aluminum alloy 319 , normal condition.

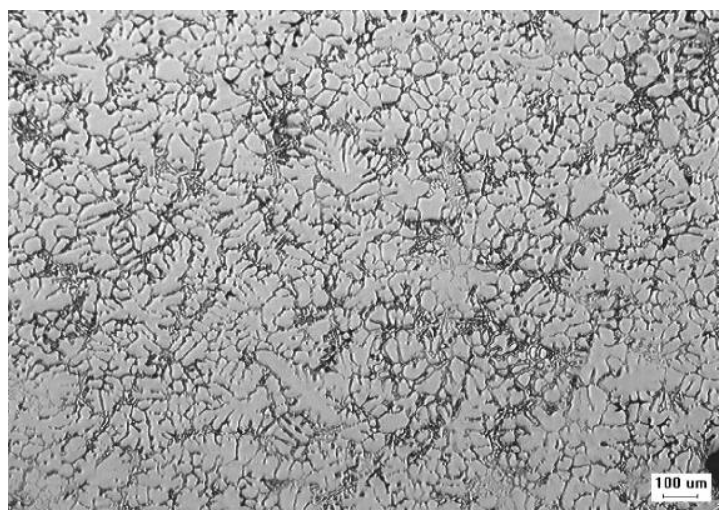

(a) No vibration; casting temperature, $650^{\circ} \mathrm{C}$

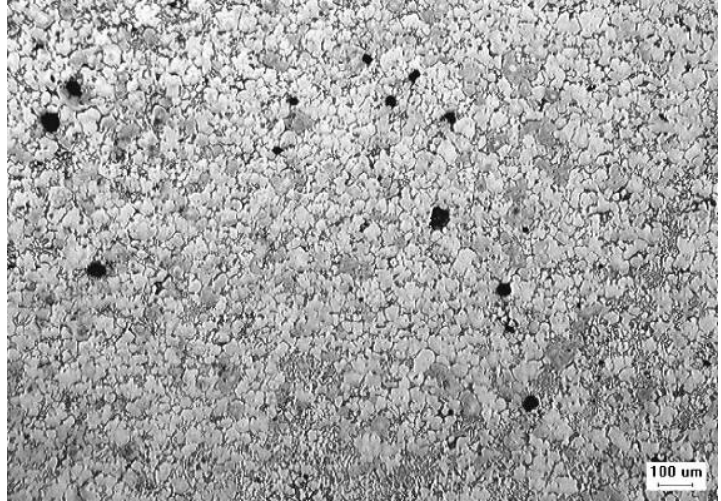

(b) With vibration; casting temperature, $640^{\circ} \mathrm{C}$

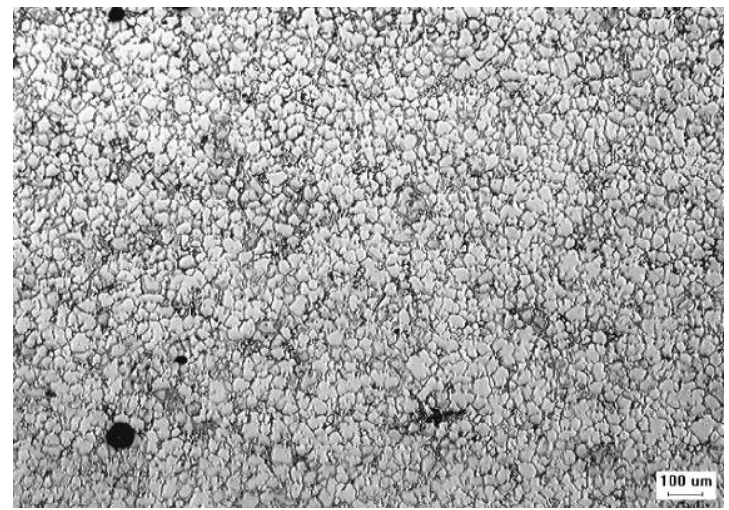

(c) With vibration; casting temperature, $650^{\circ} \mathrm{C}$

Fig. 5.18. Microstructure of aluminum alloy 319 without and with $100 \%$ amplitude vibration after 60-s exposure. Ultrasonic processing greatly improved the microstructure of the alloy. 


\subsubsection{A354 Alloy}

Aluminum alloy A354 was cast without and with ultrasonic processing in both a 250 -g metal mold and a 2-kg metal mold under conditions derived from the thermodynamic simulation. Ultrasonic vibration was begun right before casting. The ultrasonic amplitude was $100 \%$, and the output power was $10-15 \%$ of full power. Processing time was $60 \mathrm{~s}$.

Figure 5.19a shows the microstructure of a specimen of the A354 alloy processed without ultrasound, while Fig. 5.19b-c shows the microstructures resulting from exposure to ultrasonic energy at different casting temperatures.

It can be seen that upon ultrasonic vibration, the dendritic primary face-centered cubic (fcc) aluminum was broken into fine, globular grains, while the morphology of second phases was also modified. The A354 aluminum alloy is used mainly in the aerospace industry, where outstanding strength characteristics are required. In general, a fine as-cast microstructure improves mechanical properties owing to the increased yield strength as well as toughness. Fine second phases such as eutectic silicon enhance toughness properties, especially ductility and fatigue toughness. The enhanced microstructure will also lead to reduced scrap rate of casting, resulting in energy and cost savings.

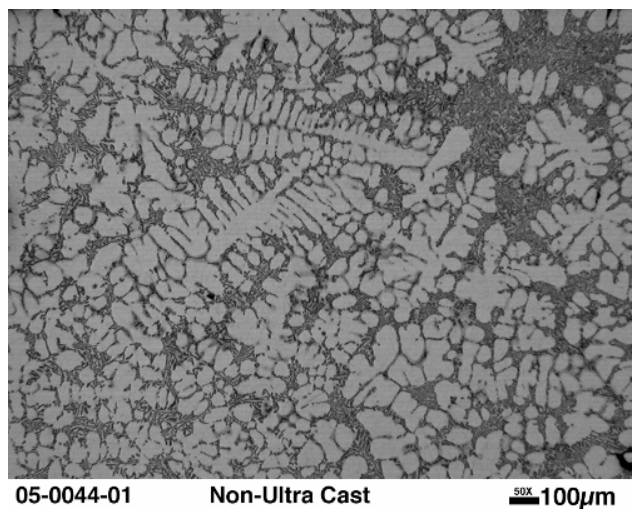

(a) No vibration; note the fully developed dendrites

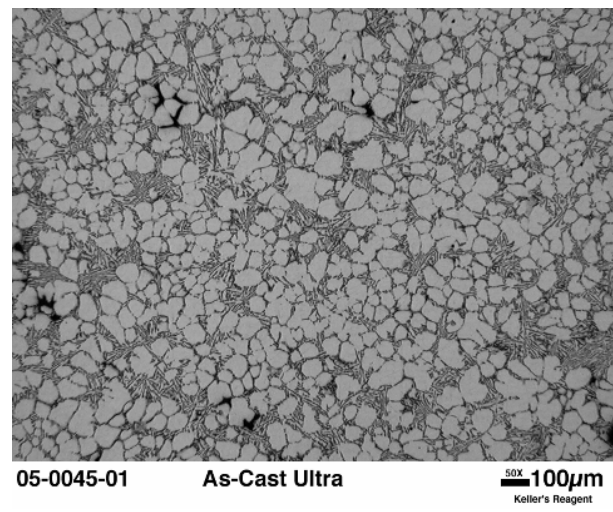

(b) With vibration

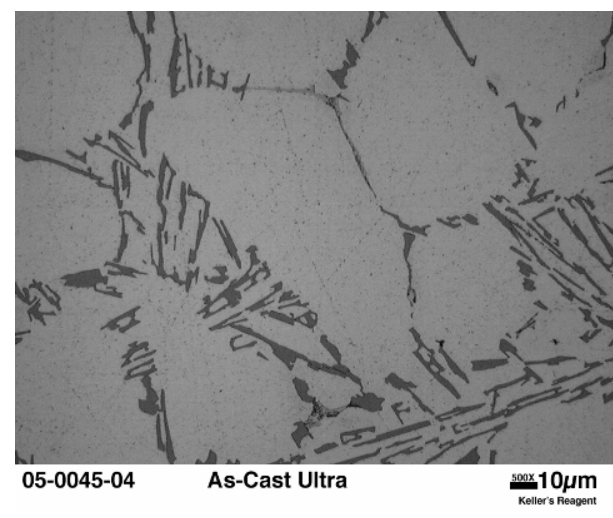

(c) Fig. (b) at higher magnification

Fig. 5.19. Microstructure of A354 alloy without and with ultrasonic processing. It is clearly seen that with ultrasonic vibration the dendrites were removed. Fine globular primary aluminum grains were obtained, and the eutectic silicon phase was also refined. 


\subsubsection{Modification in Second Phases}

Figure 5.20 shows the significant difference in eutectic silicon morphology that can be seen in specimens without and with ultrasonic processing. The eutectic silicon particles appear in coarse, long acicular form in a specimen not subjected to ultrasound (Fig. 5.20a), while they are well modified and extremely fine in a specimen treated with ultrasonic vibration (Fig. 5.20b).

Table 5.1 shows the quantitative characterization of eutectic silicon particles. With ultrasonic processing the mean particle area is about $1 / 400$ and the mean particle length about 1/30 the area of particles in materials not treated with ultrasonic vibration.

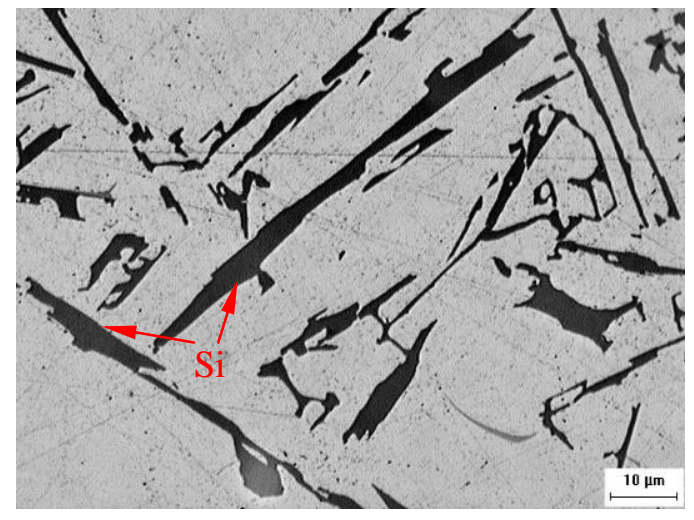

(a) No vibration

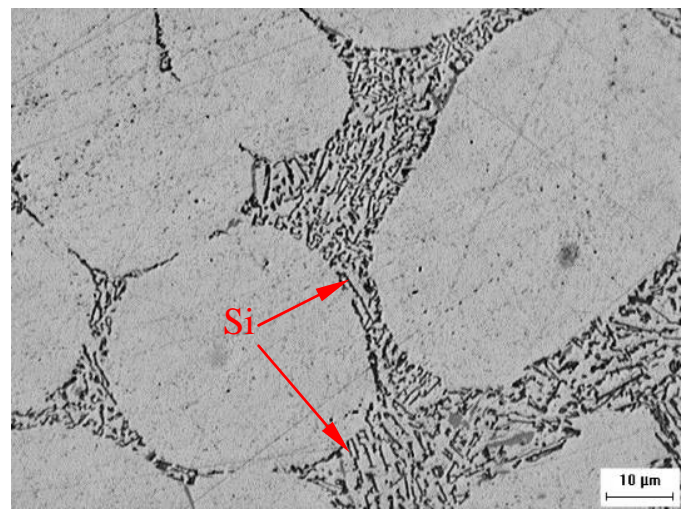

(b) Vibrated at $70 \%$ amplitude for $60 \mathrm{~s}$

Fig. 5.20. Effect of ultrasonic vibration on eutectic silicon structure (small dark structures) in aluminum alloy A356 as seen under optical microscope. Casting temperature was $630^{\circ} \mathrm{C}$. Results show that the eutectic silicon phase was drastically refined with ultrasonic processing.

Table 5.1. Characteristics of eutectic silicon particles corresponding to specimens in Fig. $\mathbf{5 . 2 0}$

\begin{tabular}{lcc}
\hline Specimen & $\begin{array}{c}\text { Mean Si particle area } \\
\left(\mu^{2}\right)\end{array}$ & $\begin{array}{c}\text { Mean Si particle length } \\
(\mu \mathrm{m})\end{array}$ \\
\hline Without ultrasonic vibration & 201.3 & 28.0 \\
With ultrasonic vibration & 0.51 & 1.01 \\
\hline
\end{tabular}


Figure 5.21 shows the three-dimensional morphology of eutectic silicon observed with SEM on the deep-etched specimens without and with ultrasonic treatment. The eutectic silicon is greatly affected by ultrasonic vibration and exhibits a coral-like form, whereas it has a typical plate-like form without ultrasonic vibration.

Both the primary aluminum and the eutectic silicon structures are improved with ultrasonic vibration. The improvement shown in our experiments implies that ultrasonic vibration might be an effective way of improving the mechanical properties of A356 alloy castings. These experiments again prove the effectiveness of ultrasonic processing on aluminum alloys; this technology may lead to significant energy savings.

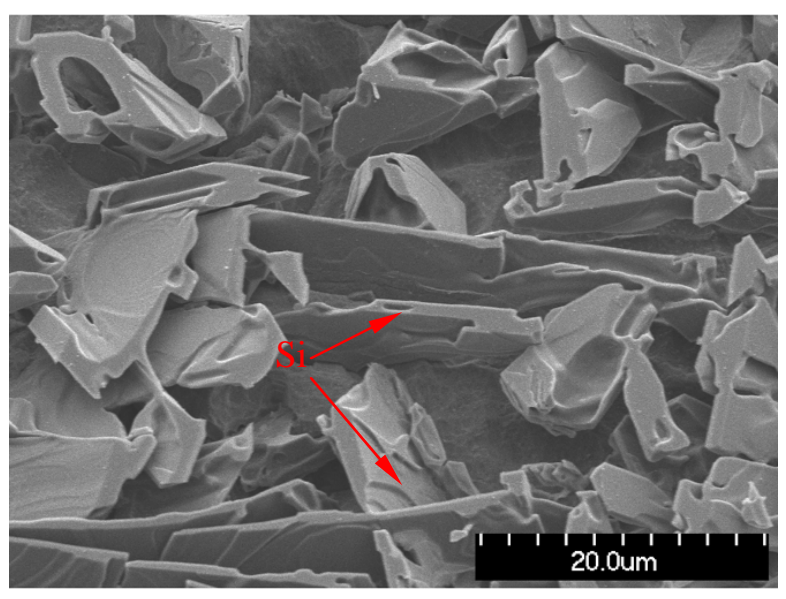

(a) No vibration

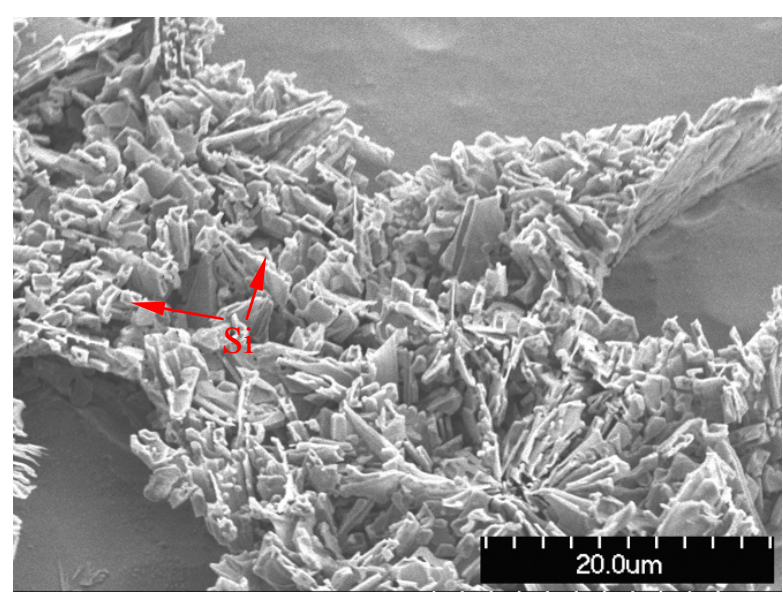

(b) Vibrated at $70 \%$ amplitude for $60 \mathrm{~s}$

Fig. 5.21. Effect of ultrasonic vibration on eutectic silicon structure in aluminum alloy A356 as seen with SEM. Specimens were deeply etched. Casting temperature was $630^{\circ} \mathrm{C}$. Fine rosette-like silicon phase was obtained with the ultrasonically processed specimen.

\subsection{Grain Refinement of 4340 Steel}

Steel alloy 4340 was melted in an induction furnace, and poured into a graphite mold with $20 \mathrm{kHz}$ acoustic energy applied onto the outside surface of the mold. Acoustic energy was applied for $120 \mathrm{~s}$. The melt was then allowed to cool very quickly. Results show a significant difference between the conventionally processed specimens and those to which acoustic energy was applied (Fig. 5.22). Fully developed dendrites developed on the specimen that did not receive ultrasonic processing, while fine globular grains were obtained on the specimens ultrasonically processed at both temperatures. The results shown here indicate that if ultrasonic processing is applied in the steel industry, this technology will lead to considerable energy savings during the subsequent heat-treating operations of these fine-grained materials. This is because a much shorter time and a lower temperature will be required to heat-treat fine-grained steels. 


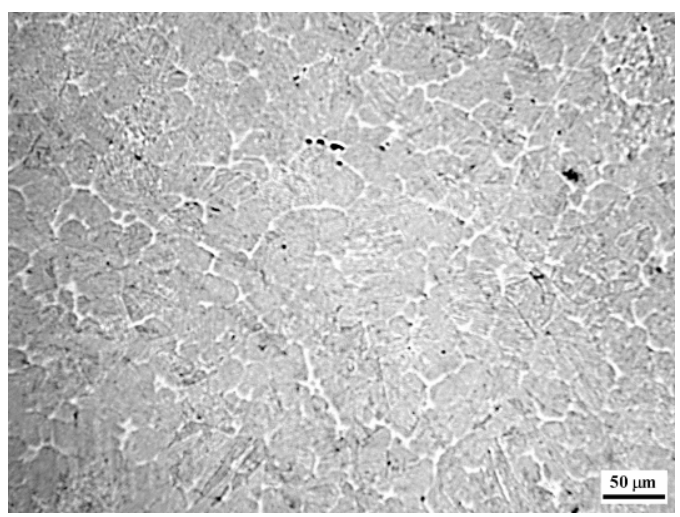

(a) No vibration; casting temperature, $1525^{\circ} \mathrm{C}$

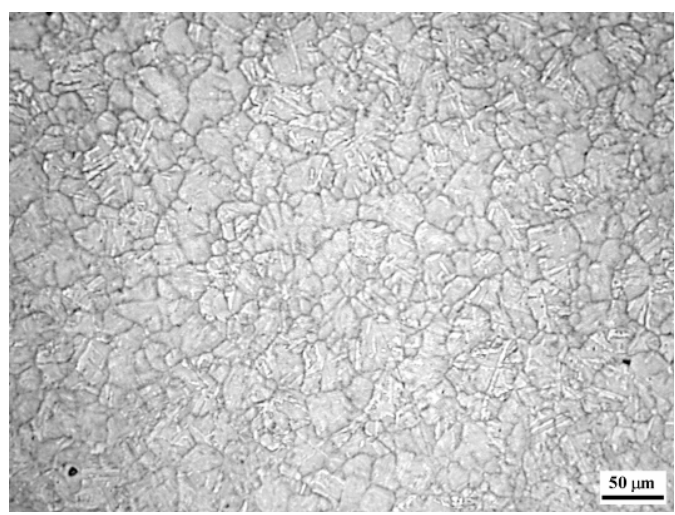

(b) With vibration; casting temperature, $1548^{\circ} \mathrm{C}$

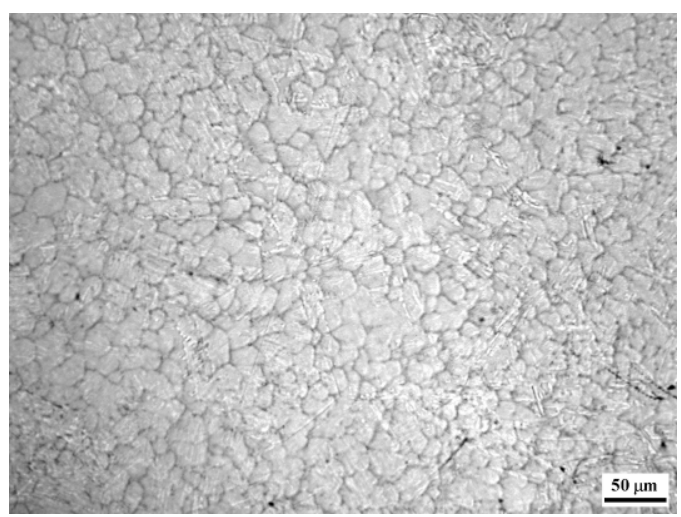

(c) With vibration; casting temperature, $1516^{\circ} \mathrm{C}$

Fig. 5.22. Microstructure of 4340 steel without and with $100 \%$ ultrasonic amplitude and 120 -s exposure time. Fully developed dendrites were observed on the specimen without ultrasonic processing, while fine globular grains were obtained on the specimens ultrasonically processed at both temperatures.

\subsection{Parameters Affecting Grain Refinement during Ultrasonic Processing}

\subsubsection{Ultrasonic Intensity}

To examine the effect of acoustic energy on grain structure, experiments that involved adjusting the ultrasonic amplitude were carried out, since the intensity of acoustic energy injected into the melt is proportional to the square of ultrasonic amplitude. Four amplitudes were used during the experiments: $0 \%$ (without ultrasound), 30\%, 50\%, and $70 \%$. The casting temperature was $640{ }^{\circ} \mathrm{C}$, and the vibration duration was $60 \mathrm{~s}$. A copper mold holding up to $250 \mathrm{~g}$ of molten aluminum was used. Experimental results are shown in Fig. 5.23, and the quantitative analysis of the effect of ultrasonic amplitude is shown in Fig. 5.24. When no acoustic vibration was used (Fig. 5.23a), aluminum dendrites were fully developed and were up to several millimeters in length. The eutectic silicon is plate-like, and its length can be as much as $200 \mu \mathrm{m}$. With increasing ultrasonic amplitude, the primary aluminum grains become less dendritic and more spherical (Fig. 5.23b-d). In addition, the size and morphology of the eutectic silicon phase are also altered from coarse and acicular or lamellar form to fine fibrous form. The high acoustic intensity favors the formation of small, spherical primary aluminum grains. 


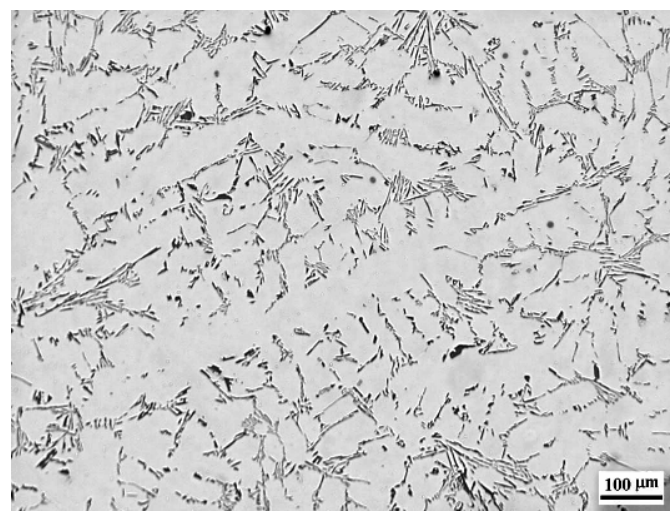

(a) $0 \%$ amplitude (no vibration)

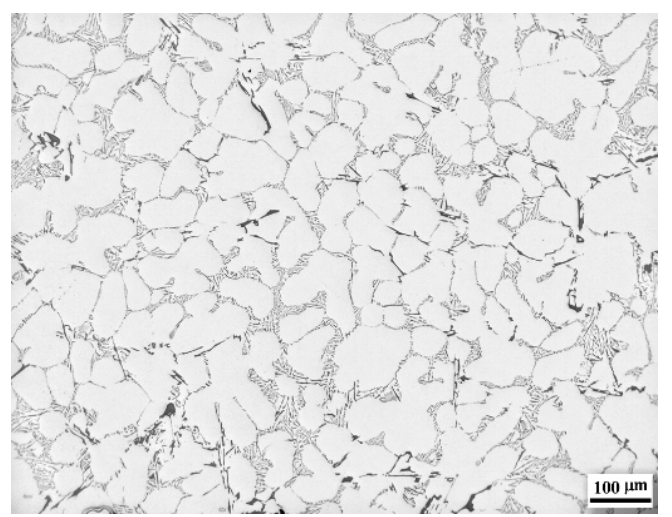

(c) $50 \%$ amplitude

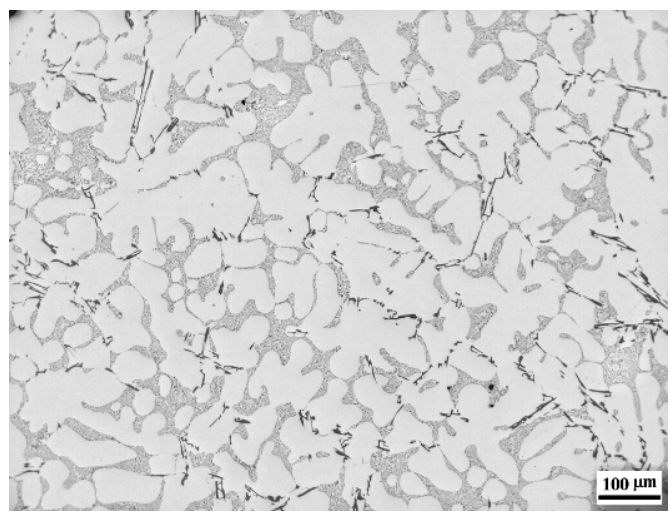

(b) $30 \%$ amplitude

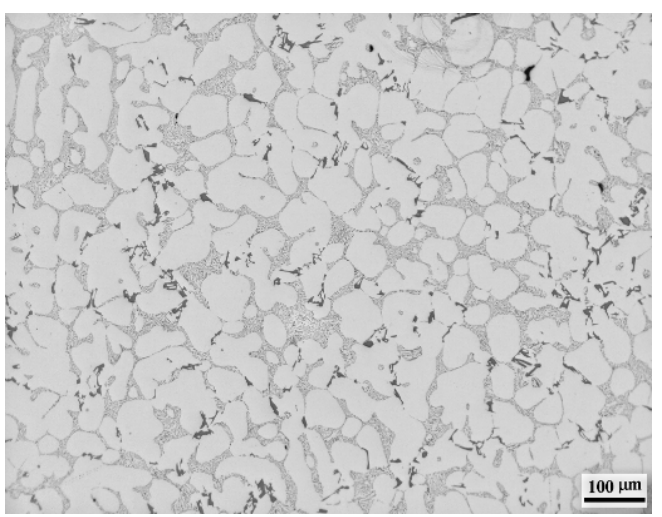

(d) $70 \%$ amplitude

Fig. 5.23. Microstructure of aluminum alloy A356 processed with varying ultrasonic amplitudes. The casting temperature was $640^{\circ} \mathrm{C}$. The specimens were vibrated for $60 \mathrm{~s}$ during solidification at an ultrasonic amplitude of $0-70 \%$.

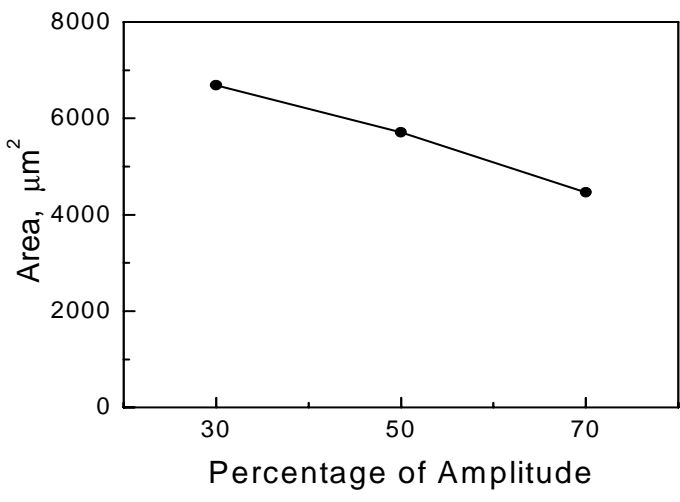

(a) Av. primary grain area

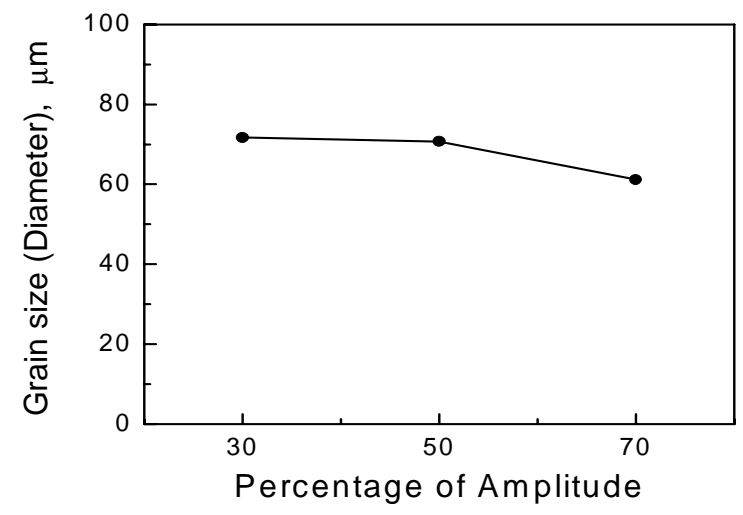

(b) Av. primary grain size

Fig. 5.24. Quantitative analysis of the effect of ultrasonic amplitude. The casting temperature was $640^{\circ} \mathrm{C}$. Grain size decreased with increasing ultrasonic vibration amplitude. 


\subsubsection{Casting Temperature}

Experiments were also conducted to determine the optimum casting temperature with ultrasonic vibration. The results are shown in Fig. 5.25. Quantitative analysis of the effect of ultrasonic amplitude is shown in Fig. 5.26. It can be seen (Fig. 5.26b) that the size of the primary aluminum grain decreases with decreasing casting temperature, reaches a minimum size at $630^{\circ} \mathrm{C}$, and then increases slightly with slightly decreasing casting temperature.

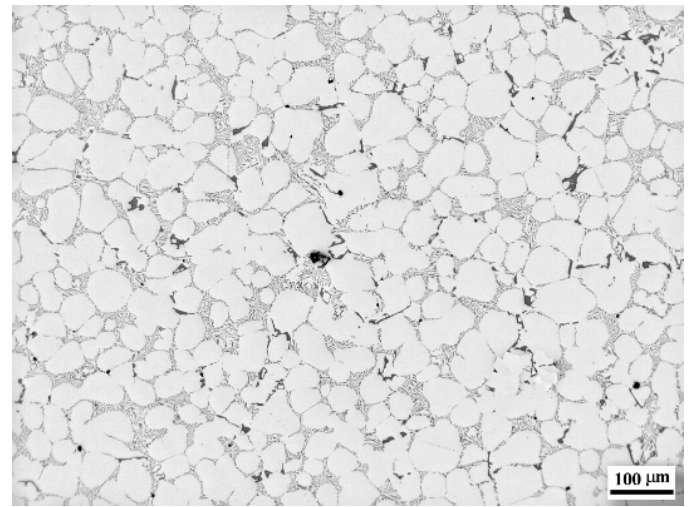

(a) Casting temperature, $620^{\circ} \mathrm{C}$

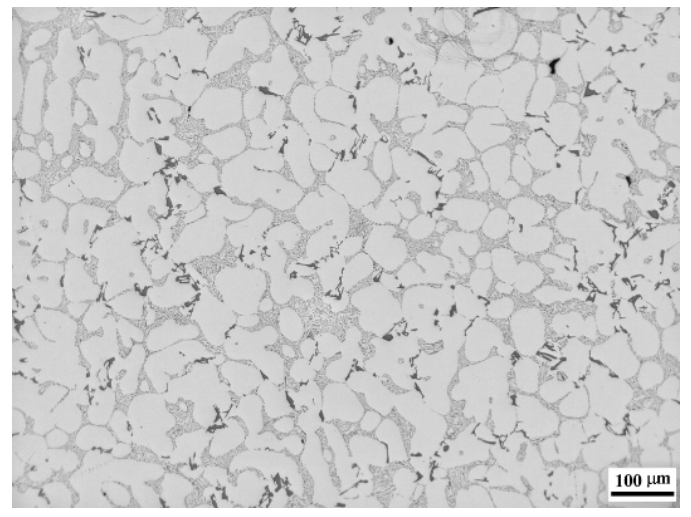

(c) Casting temperature, $640^{\circ} \mathrm{C}$

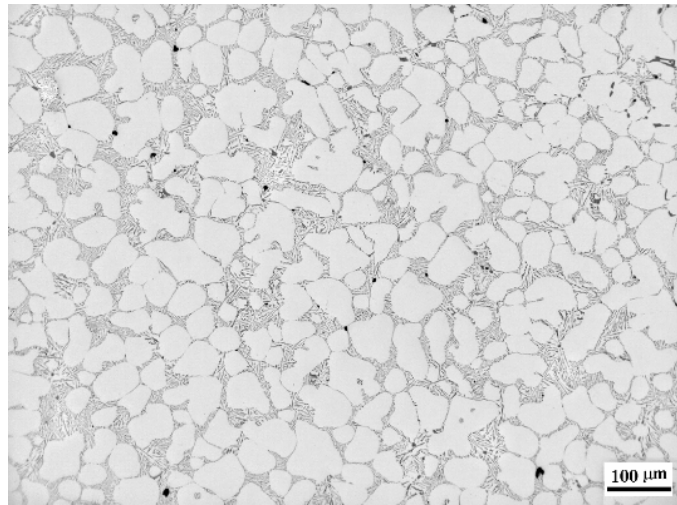

(b) Casting temperature, $630^{\circ} \mathrm{C}$

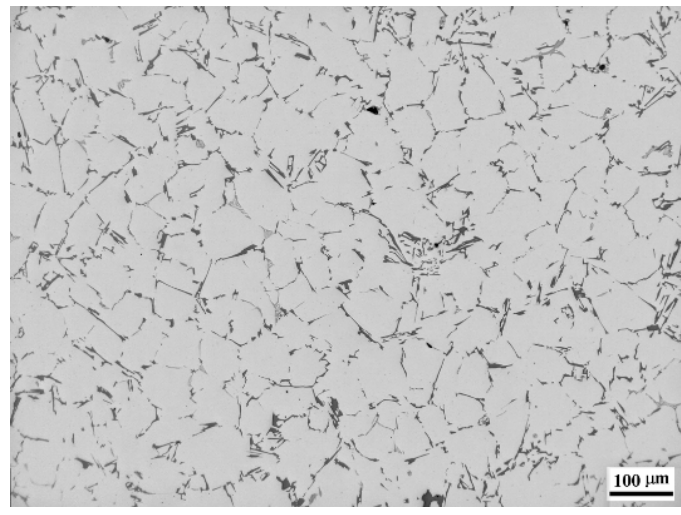

(d) Casting temperature, $655^{\circ} \mathrm{C}$

Fig. 5.25. Effect of casting temperature on as-cast microstructure of A356 alloy with ultrasonic vibration at $70 \%$ amplitude for $60 \mathrm{~s}$. Grain sizes are smaller at lower casting temperatures. 


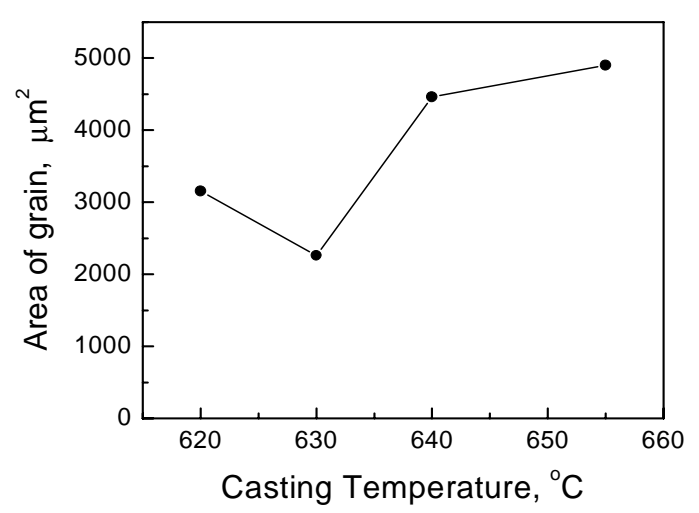

(a) Av. primary aluminum grain area

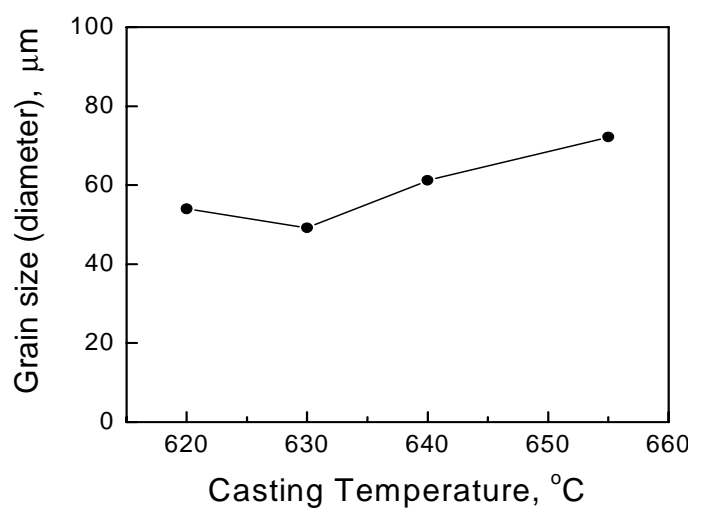

(b) Av. primary aluminum grain size

Fig. 5.26. Quantitative analysis of the effect of casting temperature with ultrasonic vibration of $70 \%$ amplitude. The grain sizes are smaller at lower casting temperatures but smallest at a casting temperature of $630^{\circ} \mathrm{C}$.

\subsection{Mechanisms for Ultrasonic Influence on Solidification}

Several researchers have proposed mechanisms by which refined globular grains are produced via ultrasonic vibrations $[1,4]$. These mechanisms are related to ultrasonically induced dendrite fragmentation and heterogeneous nucleation.

It is well known that isothermal coarsening can be used to produce a globular microstructure in an aluminum alloy if the specimen is held at semisolid temperatures for an extended time [9]. Electromagnetic stirring can also be applied to a solidifying alloy to obtain globular grains at fairly short processing times [10]. In fact, both isothermal coarsening and electromagnetic stirring were successfully used for the production of globular, nondendritic microstructures by the dendritic fragmentation mechanisms.

In order to determine if dendrite fragmentation is the mechanism for ultrasonic grain refinement in alloys, we injected ultrasonic energy into an aluminum alloy A356 at semisolid temperatures (mushy zone temperatures). The results are shown in Figs. 5.12 and 5.13, suggesting that it is difficult to obtain globular grains in a short time frame using ultrasonic vibration. This may imply that the temperature and/or pressure fluctuations induced by ultrasonic vibration are not efficient in breaking up dendrites in the mushy zone. Dendrite fragmentation requires the remelting of the secondary dendrite at their roots [11]. Remelting of a solid is usually slow because latent heat and solute have to be removed from the roots of the secondary dendrites. The temperature and pressure fluctuations occur at a frequency of $20 \mathrm{kHz}$, which may be too fast for dendrite fragmentation. Some limited dendrite fragmentation occurred in our experiments, since the grain size is reduced with acoustic vibration. The limited dendrite fragmentation can be related to the acoustic streaming in the slurry, which promotes mass transfer and thus the remelting of dendrites at their roots.

Since dendrite fragmentation does not appear to affect the formation of globular, nondendrite microstructure in the acoustically processed melt, the dominant mechanism for the formation of a globular microstructure seems to be acoustically induced heterogeneous nucleation. 
When ultrasonic vibration is applied to a melt, cavitation occurs, forming a large number of tiny discontinuities or cavities. These cavities expand and collapse essentially instantaneously. During the expansion stage, the temperature of the cavity surface drops. As a result, undercooling occurs on the cavity surfaces and results in the formation of solid phase nuclei. The nuclei thus formed can be distributed throughout the melt by acoustically induced streaming. A large number of nuclei can be produced during the expansion stage, resulting in the formation of globular grains.

Ultrasonic vibration induces heterogeneous nucleation right after pouring, while dendrite fragmentation takes place after solidification begins (at a temperature lower than the liquidus). Our experimental results suggest that cavitation-induced heterogeneous nucleation is the dominant mechanism for globular grain formation in specimens processed using acoustic vibration [12].

Having established the mechanism of globular grain formation in alloy under ultrasonic vibration, we can discuss the effect of processing parameters on the resultant microstructure of the ultrasonically processed alloy.

\subsubsection{Casting Temperature}

Figures 5.25 to 5.26 indicate that grain size decreases with decreasing temperature, reaches a minimum at $630^{\circ} \mathrm{C}$, and then increases with decreasing temperature. This can be explained by the survival of the ultrasonically induced embryos in the melt. Since these embryos are not thermodynamically stable (they are formed only at the interfaces of the cavitation bubble and the melt during the expansion stage of the cavitation bubbles), they will be dissolved after the cavitation bubbles are collapsed in the melt. The higher the temperature of the melt, the shorter the survival time will be for those embryos. As a result, fewer embryos will survive to grow into a grain at higher casting temperatures than at lower casting temperatures. When the casting temperature is closer to the liquidus temperature, the melt will be more viscous, so the formation of cavitation bubbles is more difficult, resulting in lower embryo formation than at higher temperatures. This accounts for the larger grain size obtained at both higher and lower casting temperatures. The final grain size is determined by the creation and the survival of the embryos in the melt induced by the high-intensity ultrasonic vibrations.

\subsubsection{Ultrasonic Intensity}

The intensity of the acoustic energy injected into the melt is proportional to the square of ultrasonic amplitude. As shown in Fig. 5.23, with increasing ultrasonic amplitude, the primary aluminum grains become less dendritic and more spherical (Fig. 5.23b-d). High acoustic intensity favors the formation of small, spherical primary aluminum grains. This is because ultrasonically induced cavitation will be more severe at high intensities, resulting in more heterogeneous nucleation embryos in the melt.

\subsection{Grain Refinement of Bismuth/Tin Alloy}

A bismuth/tin alloy specimen was melted at $150^{\circ} \mathrm{C}$. During the solidification process, ultrasonic vibration of $400 \mathrm{kHz}$ was introduced into the top of the melt for $20 \mathrm{~s}$. The results are shown in Fig. 5.27. Notice that the white lines are grain boundaries. The differences in color do not necessary mean different grains. A comparison between photos (a) and (b) of the figure shows that ultrasonic vibration produced finer grains. Figure 5.27(b) also shows that the grain size increases with the increase of distance from the ultrasonic radiator. 


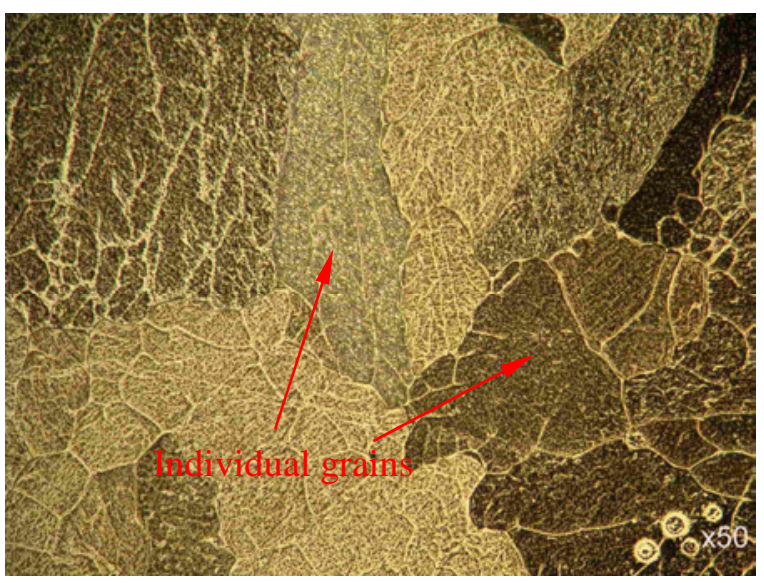

(a) No vibration

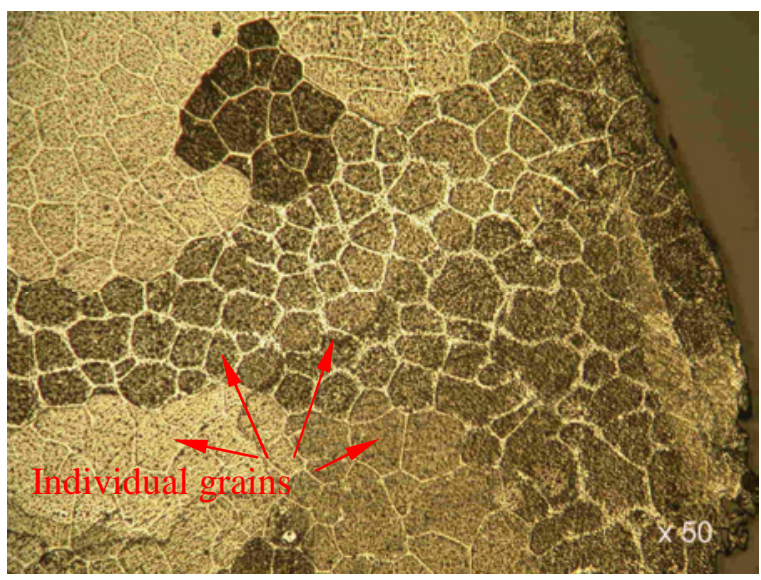

(b) 400-kHz vibration

Fig. 5.27. Microstructure of bismuth/tin alloy without and with $400-\mathrm{kHz}$ vibration and varying ultrasonic amplitude. It can be clearly seen that grain refinement was obtained upon high-frequency ultrasonic processing. The white lines are the grain boundaries. 



\section{Accomplishments}

All the objectives for this project were accomplished. It was shown that the introduction of ultrasonic energy is very useful for the degassing and grain refinement of 4340 steel and many aluminum alloys, including A356, A354, 319, 3004, 6061, and 6063. As a result of this work, a patent was filed, six papers were published, and several presentations were made.

Energy benefits from the results of this project, can occur through a number of avenues:

1. Result: Ultrasonics leads to much more rapid removal of hydrogen from molten aluminum.

a. Energy benefits accrue from less dross formation because of a shorter time at degassing temperature.

b. Productivity increases due to the shorter processing time.

c. Environmental benefits accrue from the elimination of fluorine gas from the process.

2. Result: Ultrasonics leads to much-finer-grained material.

a. Energy benefits can accrue from a reduction in time and temperature in the homogenization processes for steel and aluminum alloys. Steel currently requires $\sim 24 \mathrm{~h}$ homogenization; the new estimate for processing time is $16 \mathrm{~h}$. Aluminum currently requires $\sim 8 \mathrm{~h}$; the new process is estimated to require $6 \mathrm{~h}$.

b. Energy benefits can also accrue from reducing the scrap rate for steel or aluminum (currently $\sim 5 \%$; new process est. $\sim 3 \%$ ). This could occur in the following processes: direct chill casting, continuous casting, die casting, and permanent mold casting.

c. Energy benefits can also accrue by the elimination of grain refiners in aluminum processing.

\subsection{Patents}

A patent application entitled "Method and Apparatus for Semi-Solid Material Processing" by Q. Han, X. Jian, H. Xu, and T. T. Meek (ORNL Docket No. 1372, 2004) has been filed.

\subsection{Publications and Presentations}

The following publications and presentations resulted from this project:

1. X. Jian, C. Xu, T. Meek, and Q. Han, "The Effect of Ultrasonic Vibration on the Solidification Structure of A356 Alloy," AFS Transactions 2005, 5-85.

2. X. Jian, H. Xu, T. T. Meek, and Q. Han, "Effect of Power Ultrasound on Solidification of Aluminum A356 Alloy," Materials Letters 59, nos. 2-3 (February 2005): 190-193.

3. Hanbing Xu, Xiaogang Jian, Thomas T. Meek, and Qingyou Han, "Degassing of Molten Aluminum A356 Alloy Using Ultrasonic Vibration," Materials Letters 58, no. 29 (November 2004): 3669-3673.

4. X. Jian, Q. Han, H. Xu, and T. T. Meek, "Solidification of Aluminum Alloy A356 under Ultrasonic Vibration," pp. 73-79 in Solidification of Aluminum Alloys, ed. M. G. Chu, 
D. A. Granger, and Q. Han (Warrendale, Penn.: The Minerals, Metals \& Materials Society, 2004), 73-79.

5. H. Xu, X. Jian, Q. Han, and T. T. Meek, "Investigation of Ultrasonic Degassing in Molten Aluminum A356 Alloy," presented at the Light Metals 2004 Annual Meeting, March 14-18, 2004, Charlotte, N.C., in Proceedings of the Light Metals 2004 Annual Meeting, ed. A. T.

Tabereaux (Warrendale, Penn.: The Minerals, Metals \& Materials Society, 2004), 731-735.

6. X. Jian, H. Xu, T. T. Meek, S. Viswanathan, and Q. Han, "Ultrasonic Solidification of Aluminum A356 Alloy," presented at the Third International Conference on Light Materials for

Transportation Systems (LiMAT-2003), Nov. 2-6, 2003, Honolulu, Hawaii.

\subsection{Technology Transfer}

Intellectual property has been generated from this research effort. A patent application has been filed. Several U.S. companies have signed nondisclosure agreements with Oak Ridge National Laboratory (ORNL) and are evaluating the technology.

Project participants have used several mechanisms to inform industries of the research results and advance commercialization: (1) conducting review meetings at industrial sites and at ORNL;

(2) making presentations at national meetings organized by the Minerals, Metals, and Materials Society (TMS), the American Society of Metals (ASM), and the American Foundry Society (AFS); and (3) making presentations at industrial locations and for organizations such as the North American Die Casting Association (NADCA) and AFS.

Companies who have expressed interest in the technology during this endeavor include Alcoa, Amcast Automotive, American Forging Association, Carpenter Technologies Corp., GM, IdraPrince, Holset Turbochargers, Lunt Manufacturing, Mercury Marine, NADCA, Ohio Valley Aluminum, Pyrotek, Queen City Forging, and Secat. 


\section{Summary and Conclusions}

Ultrasonic processing has a significant effect on the as-cast microstructure of many aluminum alloys and specialty steels. Under various experimental conditions, fine globular grains were obtained instead of large dendritic grains. Ultrasonic vibration significantly modified the solidification structure of these materials. Nondendritic globular grains were obtained in specimens solidified under ultrasonic vibration. The mean grain size of the primary aluminum grains can be as small as $30 \mu \mathrm{m}$ in specimens subjected to ultrasonic vibration, as compared with grain sizes as large as a few millimeters in specimens prepared without ultrasonic vibration. The morphology and size of the eutectic silicon phase are also altered. The length of eutectic silicon is about $1 \mu \mathrm{m}$ in specimens treated ultrasonically but is about $30 \mu \mathrm{m}$ in specimens not processed this way. It is expected that ultrasonic processing can be used to improve the mechanical properties of castings. This technology has the advantage of better energy efficiency compared to traditional technologies, including the use of grain refiners.

With increasing ultrasonic amplitude, the primary aluminum grains become less dendritic and more spherical. The size and morphology of the eutectic silicon phase are also altered from coarse and acicular or lamellar (without ultrasonic processing) to a fine fibrous form (with ultrasonic processing at different amplitude. High ultrasonic amplitude/intensity favors the formation of small, spherical aluminum grains.

With ultrasonic processing, when casting temperature is increased from 620 to $650^{\circ} \mathrm{C}$, the size of the primary aluminum grain decreases with decreasing casting temperature, reaches a minimum at $630^{\circ} \mathrm{C}$, and then increases slightly with slightly decreasing casting temperatures.

The results obtained in isothermal, intermittent, and continuous ultrasonic processing experiments may imply that there is a limited effect of dendrite fragmentation on the formation of globular, nondendrite microstructure in the acoustically processed melt. Acoustically induced heterogeneous nucleation seems to be the dominant mechanism for the formation of a globular microstructure. This gives a better understanding of the mechanism of ultrasonic processing.

Degassing performed with ultrasonic vibration resulted in a steady-state hydrogen concentration within a few minutes, regardless of the initial hydrogen concentration in the melt. The dynamics of hydrogen evolution as a function of processing time, melt temperature, and initial hydrogen

concentrations was investigated. It was suggested that ultrasonic vibration can be used to reduce the formation of porosity in aluminum alloys.

The benefits of a full-scale implementation of the new ultrasonic processing technology would be significant across various industrial sectors, including steel, aluminum, metal casting, and forging. The experimental results suggest that ultrasonic processing has the potential for scale-up for the production of critical metal components, leading to energy savings, cost reductions, and many other benefits. 



\section{Recommendations}

Future studies should include an investigation of the primary mechanism of ultrasonic vibration on the eutectic structures in aluminum alloy A356. It is highly recommended that the research reported in this study be continued and that the application and commercialization of this technology, as described in the Patent Docket No. 1372, be pursued.

There are a number of applications for this technology. Ultrasonics may be incorporated into a die casting machine to dramatically increase the integrity and properties of die castings. It may be used for producing semisolid feedstock directly from molten metal. Ultrasonic techniques can also find applications in the forging industry by enabling the processing of alloys that are difficult to cast. The research team for this project is seeking industrial partners to develop the technology to the next level. 



\section{References}

1. O. G. Abramov, High-Intensity Ultrasonics (Amsterdam: Gordon and Breach Science Publishers, 1998).

2. C. Liu, Y. Pan, and S. Aoyama, pp. 439-447 in Proceedings of the 5th International Conference on Semi-Solid Processing of Alloys and Composites, ed. A. K. Bhasin, J. J. Moore, K. P. Young, and S. Midson (Golden, Colo.: Colorado School of Mines, 1998).

3. L. D. Rozenberg, ed., Sources of High-Intensity Ultrasound, vols. 1-2 (New York: Plenum Press, 1969).

4. G. I. Eskin, Ultrasonic Treatment of Light Alloy Melts (Amsterdam: Gordon and Breach Science Publishers, 1998).

5. G. Sutton, "Photoelastic Study of Strain Waves Caused by Cavitation," Journal of Applied Mechanics 24 (1957): 340.

6. J. E. Gruzleski and B. M. Closset, The Treatment of Liquid Aluminum-Silicon Alloy (Des Plaines, Ill.: American Foundry Society, 1990), 170.

7. H. Mulazimoglu, N. Handiak, and J. E. Gruzleski, "Some Observations on the Reduced Pressure Test and the Hydrogen Concentration of Modified A356 Alloy," AFS Transactions, 1990, 225232.

8. ASM Handbook Committee, Metals Handbook, 9th ed. (Metals Park, Ohio: ASM International, 1988), 15:459.

9. E. D. Manson-Whitton, I. C. Stone, J. R. Jones, P. S. Grant, and B. Cantor, "Isothermal Grain Coarsening of Spray Formed Alloys in the Semi-Solid State," Acta Materialia 50, no. 10 (June 2002): 2517-2535.

10. D. Brabazon, D. J. Browne, and A. J. Carr, "Mechanical Stir Casting of Aluminium Alloys from the Mushy State: Process, Microstructure, and Mechanical Properties," Materials Science and Engineering A 326, no. 2 (2002): 370-381.

11. Weimin Mao, Yanjun Li, Aimin Zhao, and Xueyou Zhong, "The Formation Mechanism of Nondendritic Primary $\alpha$-Al Phase in Semi-Solid AlSi7Mg Alloy," Science and Technology of Advanced Materials 2, no. 1 (March 2001): 97-99.

12. X. Jian et al., "Effect of Power Ultrasound on Solidification of Aluminum A356 Alloy," Materials Letters 59, nos. 2-3 (2005): 190-193. 



\section{Appendix: Publications}

X. Jiana, H. Xua , T.T. Meeka, and Q. Han, "Effect of power ultrasound on solidification of aluminum A356 alloy," Materials Letters 59 (2005): 190-193.

Hanbing Xu, Xiaogang Jian, Thomas T. Meek, and Qingyou Han, "Degassing of molten aluminum A356 alloy using ultrasonic vibration," Materials Letters 58 (2004): 3669-3673. 
